\title{
Expanding the care continuum for HIV/AIDS: Bringing carers into focus
}

Jessica Ogden

Simel Esim

Caren Grown

Follow this and additional works at: https://knowledgecommons.popcouncil.org/departments_sbsr-hiv

Part of the Demography, Population, and Ecology Commons, Health Policy Commons, Immune System Diseases Commons, International Public Health Commons, Medicine and Health Commons, Public Health Education and Promotion Commons, Social Policy Commons, and the Virus Diseases Commons How does access to this work benefit you? Let us know!

\section{Recommended Citation}

Ogden, Jessica, Simel Esim, and Caren Grown. 2004. "Expanding the care continuum for HIV/AIDS: Bringing carers into focus," Horizons Final Report. Washington, DC: Population Council and International Center for Research on Women. 


\section{Expanding the Care Continuum For HIV/AIDS: Bringing Carers into Focus}

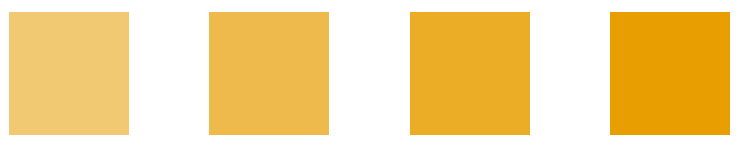

International Center for Research on Women Horizons Program 


\title{
Expanding the Care Continuum for HI V/ AI DS: Bringing Carers into Focus
}

\author{
Jessica Ogden \\ Simel Esim \\ Caren Grown
}

International Center for Research on Women

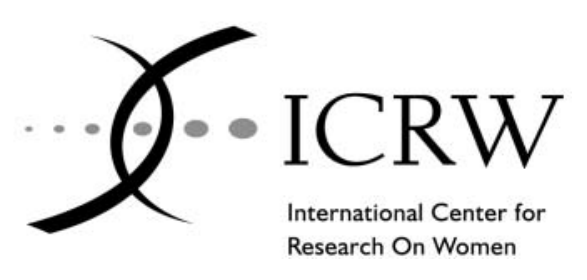


Suggested citation: Ogden, Jessica, Simel Esim, and Caren Grown. 2004. "Expanding the Care Continuum for HIV/AIDS: Bringing Carers into Focus," Horizons Report. Washington, DC: Population Council and International Center for Research on Women.

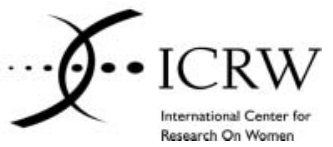

International Center for Research on Women (ICRW) is a private, nonprofit organization dedicated to improving the lives of women in poverty, advancing equality and human rights, and contributing to broader economic and social wellbeing. ICRW accomplishes this, in partnership with others, through research, capacity building, and advocacy on issues affecting women's economic, health and social status in low- and middle-income countries.

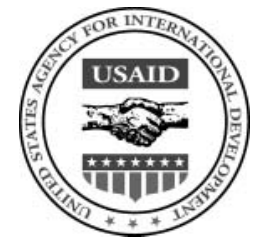

This research was supported by the Horizons Program, which is implemented by the Population Council in collaboration with the International Center for Research on Women, International HIV/AIDS Alliance, Program for Appropriate Technology in Health, Tulane University, Family Health International, and Johns Hopkins University. Horizons is funded by the U.S. Agency for International Development, under the terms of HRN-A-00-97-00012-00. The opinions expressed herein are those of the authors and do not necessarily reflect the views of the U.S. Agency for International Development.

Published in June 2004.

\section{(1) Population Council}

The Population Council is an international, nonprofit, nongovernmental institution that seeks to improve the well-being and reproductive health of current and future generations around the world and to help achieve a humane, equitable and sustainable balance between people and resources. The Council conducts biomedical, social science, and public health research and helps build research capacities in developing countries. Established in 1952, the Council is governed by an international board of trustees. Its New York headquarters supports a global network of regional and country offices.

Copyright (C) 2004 The Population Council Inc.

This document may be reproduced in whole or in part without permission of the Population Council provided full source citation is given and the reproduction is not for commercial purposes. 


\section{Acknowledgments}

The authors would like to thank the Horizons Program for funding this paper. We would also like to thank Ellen Weiss (Horizons/ICRW), Cindy Berman (then ILO, now Commonwealth Secretariat), Stephanie Urdang and Nazneen Damji (UNIFEM), Ann McCauley (Horizons/ICRW), Sarah Kambou (ICRW), Geeta Rao Gupta (ICRW) and other colleagues at ICRW for their valuable input and suggestions. Monica Agarwal (ICRW) provided research assistance for the paper. We are grateful to those who reviewed the first draft of the paper for their insights and course corrections, which were vital in making this paper complete. Many others were helpful in identifying resources, potential sites and people to be interviewed and who contributed to this process, notably Geoff Foster, Chris Castle, and Laelia Gilborn. We are also grateful to our many colleagues "at the rock face" who took precious time out from their work providing care to those in need to respond to our request for information and send us details of their programs. 



\section{Table of Contents}

Introduction 1

Background and definitions of key terms $\quad 2$

Linked and unlinked care $\quad 3$

Care economy 4

The Care Economy in the Context of the AI DS Pandemic 5

$\begin{array}{ll}\text { The burden of care } & 6\end{array}$

$\begin{array}{ll}\text { Who provides care in the home? } & 7\end{array}$

HIV / AIDS scenarios of care 9

$\begin{array}{ll}\text { Challenges faced by unlinked family care providers } & 14\end{array}$

$\begin{array}{ll}\text { Challenges to community support } & 17\end{array}$

The Health Sector Response 21

The impact of HIV and AIDS on hospitals and the health care system 22

Shifting clinical care to the home and community 23

$\begin{array}{ll}\text { The comprehensive continuum of care } & 24\end{array}$

The community home-based care movement 25

$\begin{array}{ll}\text { Types of CHBC programs } & 28\end{array}$

Issues of scale and coverage $\quad 31$

Recent developments: ART and palliative care 33

Costs of unlinked care $\quad 35$ 
Non-Health Sector Responses 36

$\begin{array}{ll}\text { An integrated management approach } & 41\end{array}$

Conclusions and Recommendations 44

Recommendations for Further Research 46

$\begin{array}{ll}\text { References } & 48\end{array}$

\section{Appendixes}

A. Community and home-based care programs 55

B. Scaling Up YRG CARE 


\title{
Introduction
}

\begin{abstract}
"Who cares for the carers, and why is it taken for granted that women provide, and will continue to provide, care and support to family members and loved ones, with no sense of the cost and value of this work to society and the economy in general?" (Berman 2002).
\end{abstract}

This question is at the heart of the issue addressed by this review: "Who cares?" This is not a rhetorical question for the majority of poor people affected by HIV and AIDS. When there is a sick or dying person in the house, someone quite literally has to care, whether out of love, duty, or simply a lack of options. Indeed, research has indicated that up to 90 percent of illness care is provided in the home (WHO 2000a). Although the role that men and boys are playing as providers of care in the context of the HIV/AIDS epidemic has been poorly documented and inadequately understood, it is generally recognized that women and girls are the principal caregivers in the vast majority of homes and bear the greatest degree of responsibility for the psychosocial and physical care of family and community members - a responsibility with substantially greater weight in homes affected by HIV and AIDS. It has also been observed that in carrying out this largely unremunerated care work, women and girls are often forced to leave paid jobs, schooling and other opportunities, and that this care work displaces other health producing activities in the household and community (e.g. Steinberg et al. 2002).

The care work done by women and girls in the household, which includes the services associated with physical, social and psychological development of family members, as well as "volunteer" activities in the community that keep the social fabric in good order, is referred to in economics literature as the "care economy" (Elson 2002). These largely unpaid activities sustain families, allow children to go to school, and free the time of other household members to generate income. Many of these economic activities are unaccounted for in government statistics, and in national income and product accounts, but because they help sustain communities and nations, they can be thought of as a public service in the production of public goods (Folbre 1994a and b). The current public finance environment, which encourages governments to spend less on social development sectors, has generated a "care gap" which women frequently subsidize with their own time, energy and resources. There are substantial costs involved, however, for the household and for the women themselves.

This review explores the specific issues that cluster around the provision of "care" in the context of the global HIV/AIDS pandemic. The care economy provides an important lens through which to view the HIV/AIDS pandemic, as it illuminates the increased labor, time and other demands placed upon households and shows that the assumptions on which norms and expectations of care provision are based are increasingly being challenged. Many indigenous social safety nets that, in the pre-AIDS era, underpinned the care economy and in times of crisis enabled many households to remain viable are being eroded in highly affected communities. Various development interventions that have helped many families to manage, such as microfinance, micro-credit and incomegeneration projects, are likewise not necessarily appropriate as currently designed and implemented 


\section{Hgrizons}

for those affected by AIDS. At the same time, because most families struggle without a formal diagnosis of the disease that is affecting them, they do not have ready access to even those health sector initiatives (such as home-based care programs and others) that could provide vital support.

This review applies the care economy lens to two key sectors, health and social protection, and finds that while important strides are being made, much more needs to be known and done to enable individuals, families, and households to survive in a world shaken by AIDS. Our analysis suggests that (1) the international "care agenda" needs, as a matter of urgency, to incorporate an understanding of the care economy into its frameworks and strategies for action, with a particular focus on the caregiver, and that (2) in so doing, national level health systems would be well advised to better integrate their services with those efforts being made by other social development sectors to help households survive. In addition to arguing for an expansion of the international "care agenda," we argue that (3) specific public sector roles and responsibilities need to be defined by national governments so that the viability of their populace can be protected or, in some cases reestablished, and to provide governance in helping to shape the private and NGO sector roles. Care, we argue, provides fundamental public goods and therefore needs appropriate remuneration and support. A strategy of simply downloading responsibility for care onto women, families, and communities can no longer be a viable, appropriate or sustainable response.

\section{Background and Definitions of Key Terms}

The impetus for this project came from the United Nations Development Fund for Women (UNIFEM) and the International Labour Organization (ILO), which in planning for a "Care Economy, HIV/AIDS and the World of Work" initiative had become aware of the lack of attention being given to the important role of unpaid caregivers in mitigating the impacts of HIV/AIDS at the household level. The International Center for Research on Women (ICRW) and the Horizons Program subsequently joined the effort to compile existing evidence into one concise "state of the art" review. What we found was a resounding silence; that the role of women in HIV care outside the health sector is largely taken for granted by policymakers and program planners, and when addressed at all, it is mainly by default rather than design. Therefore the focus of the paper expanded from a review of existing literature on unpaid caregivers to include a discussion of the absence of a body of evidence on this issue, and an exploration of why this perspective is missing. The project became one of uncovering details on the provision of care by family members and the implications of the ways in which this care does and does not link with formal care provision.

In undertaking the review from January to November 2003, the project team inventoried and reviewed a wide range of literature and program documents on HIV/AIDS and provision of homebased care by family members, allowing for a flexible definition of the care economy in the context of HIV/AIDS. Experts on HIV/AIDS and the care economy in the ILO, UNIFEM, and the Horizons Program were interviewed, and a large number of electronic and written secondary data sources were searched. In addition, a request was submitted to a wide range of listservs for those in the field implementing home-based care programs to send us information regarding their program (see Appendix A for a sample of the case studies generated). While attempts were made to collect 
information throughout the developing world, the resulting analysis focuses primarily on Africa, the site of most of the literature and programmatic experience.

One of the observations emerging from this review is that confusion arises through the use of words and concepts that are based on - but often differ from - vernacular usage. Paramount among these are "care" and "support." Sometimes the term "care" is specifically defined as being limited to the domain of clinical provision, and so contrasts with the idea of "support," which is normally provided by non-medics, often in the home, embracing psychosocial, spiritual, and other nonmedical forms of care (e.g. Gilks et al. 1998). However, this degree of specification is not the norm. More often, the terms "care" and "support" are used interchangeably, conflating clinical and non-clinical care, treatment-focused activities, emotional and spiritual support, counseling, and activities that are more broadly health- or well-being-oriented (such as income-generating projects). Often, and perhaps most confusingly, as Trengrove-Jones (2001) suggests, "care" tends to be used idiomatically rather than to describe a concrete set of activities with associated funding streams, targets and accountability.

Citing Klaits (2002:4) and Livingston (2003:221-222) reminds us that care-giving in the context of the family encompasses more than merely practical concerns. Although speaking specifically about Tswana culture, the following elements are applicable to many societies and cultures. Here, alongside practical duties and tasks,

"Care entails positive healing sentiment, moral negotiations, and love (lerato), which is closely synonymous to care. The acts through which people demonstrate care and love extend well beyond daily nursing tasks and include any activity that contributes towards the welfare of others. Sharing money and food, providing labor and time, attending funerals, visiting others, are all acts of care through which people mobilize sentiment in order to strengthen or heal relationships."

\section{Linked and Unlinked Care}

In this paper, we will use the term "care" to refer to the full range of activities undertaken by family members in the home, including psychosocial support (emotional and spiritual), custodial care (cooking, cleaning, feeding, helping with toilet needs, etc.), and the ministration of remedies and treatments, and those more subtle elements such as love and "healing." We will use the terms "clinical care" or "medical care" when referring to treatment provided by trained health professionals.

There are also problems arising from the general terminology used to describe care that takes place in the home. The terms "home-based care," "homecare" and "community home-based care" are usually used interchangeably to refer to both that

Unlinked Care is the care provided in the home by unpaid and untrained family members - usually female - and friends and neighbors of those living with HIV/AIDS, which is not linked up with any formal care and support service. Up to 90 percent of illness care is provided in the home by the unlinked system of home care and up to 80 percent of AIDS-related deaths occur in the home (Uys 2003). 


\section{Hgrizons}

universe of care (clinical and non-clinical) that is provided by lay, volunteer or professional providers who are linked to programs and care (generally non-clinical) that is provided by family members who are not linked to programs. For example, Blinkhoff et al. (1999) assert that "home care" includes the "day-to-day support which a chronically ill person receives within the community, either from family members, neighbors or agencies from outside the community" (emphasis added). Similar definitions of home-based and community home-based care are offered by Gilks et al. (1998), Jackson (2002), and Russel and Schneider (2000). Aggregating these various domains under one rubric (be it "home care," "home-based care" or "community home-based care") has allowed for the distinct benefits and costs of "unlinked" care to get lost.

\section{Care Economy}

The concept of the care economy has emerged recently in the economics literature. This concept encompasses many of the aspects of care and home-based care described above but focuses especially on the economic costs and benefits of care, the division of labor involved in various types of care, and the contribution of care to economic growth and development. Specifically, the care economy concept describes the unpaid provisioning ("non-market work") that is carried out in households and communities, primarily by women. Elson (2002) distinguishes three types of nonmarket work: subsistence production, which is production for home use of goods which in principle could be marketed - such as food, clothing, soft furnishings, pottery, and housing; household care work, which includes cooking, cleaning, and providing personal care for family members, friends and neighbors; and voluntary community work, which includes unpaid activity in all kinds of civic associations, such as self-help groups of mothers getting together to run a soup kitchen or to secure improvements in neighborhood safety.

The value of the time, energy and resources in the care economy is generally unrecognized and remains largely unaccounted for in most systems of national accounts (UN 1995). ${ }^{1}$ Yet, the UN estimates that the value of non-market work is substantial, constituting at least half of gross domestic product and more than half of private consumption (UN 1995). Moreover, women perform the majority of this work. Based on a limited number of time use surveys undertaken in 31 countries, the 1995 Human Development Report concluded that women worked longer hours than men in all countries where the data were available. The proportion of daily time that women devoted to non-market productive activities varied enormously by country and by rural/urban location, from 75 percent in Colombia to about 60 percent in rural Kenya. Men normally spent no more than a quarter of their work time in unpaid activities (UN 1995).

Because women's activities are generally invisible in national income accounting systems, there is an assumption among ordinary people as well as policy makers that the supply of women's labor is unconstrained and flexible. It is assumed that women can adjust their time easily and rapidly between market work and household production. Thus, it is often assumed that in response to crises or illnesses, women's labor will be the adjusting variable (Elson 1994).

\footnotetext{
${ }^{1}$ It is important to note that progress is being made in many countries to measure women's subsistence and informal labor activities.
} 


\section{The Care Economy in the Context of the AI DS Pandemic}

Caring labor has always been necessary to maintain families, but it has been additionally stretched by the HIV/AIDS pandemic. Box 1 provides a partial listing of some of the unpaid activities undertaken by women in the care economy regardless of whether or not a family member is living with HIV and AIDS.

Box 2 shows some of the additional work that must be added to this list in an AIDS-affected home. The precise activities will vary according to the circumstances of the family and stage of the illness. Clearly, the degree and burden of work involved will correlate strongly with a given household's economic standing. Better-off households can purchase food, for example, so will spend less time on agricultural activities. These households also have fewer house maintenance activities, if they are living in permanent or "modern" structures. They may also be able to hire domestic help. The vast majority of AIDS-affected households in poor countries, however, are severely and increasingly resource-constrained. This has a direct bearing on the burden of caring work they have to undertake, and also the impact of this work. The degree and types of care work also changes over the course of a person's illness-increasing in intensity as the virus progresses.

\section{Box 1 Activities undertaken by women in the care economy often include:}

- Collecting water and fuel.

- Growing, storing, preparing, cooking and serving/distributing food.

- Cleaning and washing.

- Bathing children and the sick.

- Child care and socialization.

- Ministering to the sick, including in some cases the application of home remedies, collecting (or purchasing), preparing and administering medicinal herbs or pharmaceutical preparations, accompanying the sick to health care centres, consolation, etc.

- Fostering and maintaining healthy social relationships with family and neighbors.

- Supplemental income generation (often in the informal economy). 


\section{Hgrizons}

\section{The Burden of Care}

Whenever there is a household crisis, such as an illness, the amount of time and energy required to carry out unpaid care work increases exponentially. Depending on the nature of the crisis or illness, the duration of this increased workload can be either short- or long-term. HIV/AIDS is a chronic, long-term illness-or in Barnett's classification, a "long-wave disaster" (Barnett 1991; Barnett and Blaikie 1992). Those in their prime, economically-active years are most likely to acquire HIV infection, and this has a profound impact on the ability of households to maintain viability. The impact of the disease on a household's functioning may build incrementally, and the burden of household work will increase accordingly. Oftentimes additional dependents are also taken into the home-older relatives or, increasingly, related children orphaned by the epidemic-who will also require care and attention. All of this work is layered on top of the existing care that continues to be undertaken to maintain the health and well-being of other household members, and with a decreasing amount of household income as previously productive adults sicken and eventually die. Almost everywhere, these extra burdens of care and support are borne by women, and the implications for their own health and well-being can be enormous (Akintola 2003), not least when those providing this care are themselves living with HIV.

\section{Box 2 Additional care activities in AIDS-affected home}

- Bathing the sick person and cleaning up after them.

- Obtaining food through purchase or agriculture.

- Storing, preparing and serving meals.

- Hand-feeding those too sick to feed themselves.

- Washing clothes and bed sheets.

- Escorting the sick person to and from the toilet.

- General assistance in walking (especially on stairs and uneven surfaces).

- House maintenance (particularly important where people live in mud-walled homes with thatched roofs that will need periodic maintenance and repair).

- Emotional support.

- Child care.

- Purchasing and administering drugs or remedies.

- General household survival needs such as income generation and generating food through subsistence agriculture. 
The stark realities of caring for a family member with advanced HIV disease or AIDS are ably recorded by Steinberg and colleagues (2002), although this is the only study we were able to find which documented these experiences in detail. In this survey of 771 AIDS-affected families in South Africa, they found the following:

- $\quad 16$ percent of those sick could not control their bowels and even more lacked bladder control;

- 17 percent needed help to and from the toilet and getting in and out of bed;

- About 19 percent could not wash without assistance;

- Just over 17 percent had to be helped to dress.

These authors stress the fact that all of these problems, and the care required by them, are significantly compounded by inadequate access to even the most rudimentary of sanitation facilities. Forty-three percent of respondents had tap water in their own dwelling, but 30 percent had access only to a communal tap or a natural water source such as a river or stream. Furthermore, only 20 percent of rural households surveyed had access to a flush toilet. Substantial proportions of both rural and urban households were still dependent upon pit or bucket latrines.

"Under even the best of circumstances, lack of control over bodily function is humiliating for the patient and unpleasant for the carer. But when access to a toilet is difficult and there are no proper facilities for the safe disposal of fecal matter, conditions are so much more miserable, and there is a high risk for contamination and infection of others as well" (Steinberg et al. 2002: 13).

\section{Who Provides Care in the Home?}

Although few systematic studies have been undertaken to document who provides care at the family level, it is widely acknowledged that women play a central role (see, e.g. Pizurki et al. 1987, cited in PANOS 1990). In their study of family care for those living with HIV in Uganda, Taylor et al. (1996) found that women were the primary caregivers in 86 out of 100 illness episodes, that a man was the primary care-giver in eight of these 100 episodes, and that in another eight of the episodes care was provided jointly by husband and wife. In a small South African study, Akinkole (2003) found that all but one of a sample of 21 caregivers were women. Age is also a relevant factor. In a study exploring the ways in which households "cope" with HIV/AIDS in South Africa, Steinberg et al. (2002) found that the majority of caregivers in the home were women or girls (68 percent) and that of these 7 percent were less than 18 years of age, and 23 percent were over 60 .

If women in general are heavily involved in care, elderly women are particularly involved. This involvement can make them increasingly vulnerable to poverty and illness. According to a recent "gender-aids" listserv discussion, Help Age, Kenya ${ }^{2}$ have conducted studies indicating that over 90 percent of older carers are women. In this discussion, it was argued that these older women are disproportionately affected by the impoverishing effects of the pandemic: many sell off assets to

\footnotetext{
${ }^{2}$ No reference to this study was provided
} 


\section{Hgrizons}

obtain treatment for ailing adult children; they are too busy with care to engage in incomegenerating activities, and as a result are unable to acquire daily necessities such as food and water. What nourishment these elderly caregivers are able to obtain they tend to give to others in the household, thus putting themselves in danger of becoming malnourished and unwell. Their health is further jeopardized due to a lack of access to basic materials such as gloves and water, which could put them at risk of acquiring HIV or bacterial infections. The discussion also highlighted the fact that, because information campaigns do not target the elderly, many of these carers are not even aware that their children are HIV-infected, and so do not use "universal precautions" even if they have the means to do so. This lack of knowledge about HIV can also result in these women and their families spending scarce resources in the futile search for a cure, thus sinking them deeper into poverty. Mark Gorman, deputy CEO of HelpAge International, described older people as "the forgotten and invisible army in the war against AIDS."

While adult and elderly women are usually the primary caregivers, it is important to note that men are also involved, and that this involvement may indicate a renegotiation of gender norms in the context of this epidemic. While reporting that "men are almost never the primary carers in the home," a recent UNAIDS case study also notes that, in Uganda and South Africa at least, AIDS is beginning to challenge traditional attitudes and that men are increasingly willing to take a more active role in the physical care of sick spouses and family members (UNAIDS 2000a). Taylor et al. (1996), for example, found that a full quarter of co-resident men in their study assisted with some form of direct nursing care. Men, they found, also helped by purchasing drugs and food, fetching water, providing transport for the sick person to the clinic and paying for medical expenses. More recently, perhaps in response to the 2001 World AIDS Campaign which focused on the role of boys and men in HIV/AIDS, ${ }^{4}$ a number of projects have proactively sought to involve men in the HIV/AIDS struggle in various ways, including "empowering" them to take a more active role in care provision. One such project, undertaken in Zimbabwe by ActionAid, is training male volunteers to care for those affected by HIV/AIDS and help them set up income-generating

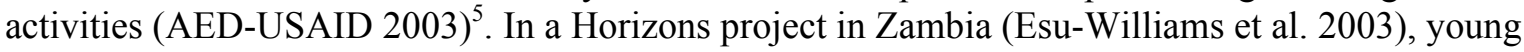
men and women who were members of school and community anti-AIDS clubs were given some basic training in home-based care for people living with HIV/AIDS, and were also given access to supplies for carrying out this care work. Training also addressed ways to support to orphans and vulnerable children in the household. The participating young men and women were equally involved in the program, with the females helping to care for an average of four people living with AIDS and four AIDS-affected children, and males helping to care for an average of four people living with AIDS and five AIDS-affected children over the course of three months. As the report points out:

"Contrary to early concerns that youth would only do tasks according to expected gender roles, researchers found that male and female caregivers provided similar kinds of care-

\footnotetext{
${ }^{3}$ See http://www.hdnet.org/13icasa/sept22_olderpeople.htm

${ }_{5}^{4}$ See http://www.unaids.org/wac/2001/Campaigndocs/youngmen.htm

${ }^{5} \mathrm{http} / / /$ sara.aed.org/publications/hiv_aids/aids_in_africa/Multisectoral_Responses-oct03.pdf (pages 33-36).

For an overview of a project encouraging boys to have gender equitable views and behaviors, go to www.promundo.org. See also Barker 2001.
} 
giving services, including counseling and housework. Although same-sex caregivers were required for bathing, the only other activity in which gender differences appeared was in contacting external organizations for assistance, which was reported by a greater proportion of males" (Esu-Williams et al. 2003:4).

The researchers felt that the training given to young people, which focused on traditional gender role expectations, contributed to nearly equal contributions to caregiving tasks by males and females.

Although these studies suggest that gender roles related to caregiving may be changing in the context of HIV, further research is needed to document the extent of male involvement in home care and to test strategies for equalizing the care burden among males and females in the household.

Children are the least acknowledged-and sometimes the most adversely affected-carers in the home (UNAIDS 2000a; Barnett and Whiteside 2002). Although it is not known how many children are currently acting as primary caregivers, their involvement will become increasingly common as the epidemic matures. According to UNAIDS (2000a), anecdotal evidence from various African countries suggest that these child carers are often very young-between 8 and 11 years old-as older siblings "tend to leave home to find work or seek survival on the streets as family poverty deepens." Child carers are often forced to leave school to take on this caregiving work, and also miss out on other opportunities such as sports, leisure, and socializing with peers. In addition, these children are put in the position of having to watch their parents and elders sicken and die, to intimately handle their bodies and excreta, to wonder and worry whether they are "doing it right" or "doing enough," while at the same time dealing with their sorrow, grief and facing an uncertain future. This situation is efficiently captured in the following quote from UNAIDS (2000a:14):

"Many children are left to cope with terrifying conditions and witness the suffering of the person they most love and depend on in the world, without skills or knowledge and often without anyone ever having talked to them directly about what is happening."

How this situation will affect the longer-term well-being of any given individual is impossible to predict and remains unassessed. The longer-term costs to society can barely be fathomed, as Barnett and Whiteside (2002: 17) suggest:

"We are talking about unsocialized, uneducated and in many instances unloved children struggling into adulthood. The cost to them as individuals remains unmeasured. The costs to the wider society are potentially enormous and already being felt and seen."

\section{HI V/ AI DS Scenarios of Care}

The care economy lens facilitates a perspective that distinguishes the care provided in the home by family members from care provided by trained individuals (sometimes paid, sometimes volunteer) who are linked to programs. Figure 1 presents four scenarios of different types of home-based care 


\section{Hgrizons}

provision. Any given household affected by HIV/AIDS will navigate among these scenarios depending on its circumstances. Although many households will remain unlinked to any program (Situation 1), others will, over time, move in and out of the other situations pictured in the diagrams. It is crucial to note, however, that whether or not they sometimes rely on support from programs, family members (mainly women) provide the bulk of care, and for the vast majority of AIDS-affected families, these caregivers are not linked to or supported by any formal HIV/AIDS care program. We refer to this domain as the "unlinked" system of care.

\section{Figure 1}

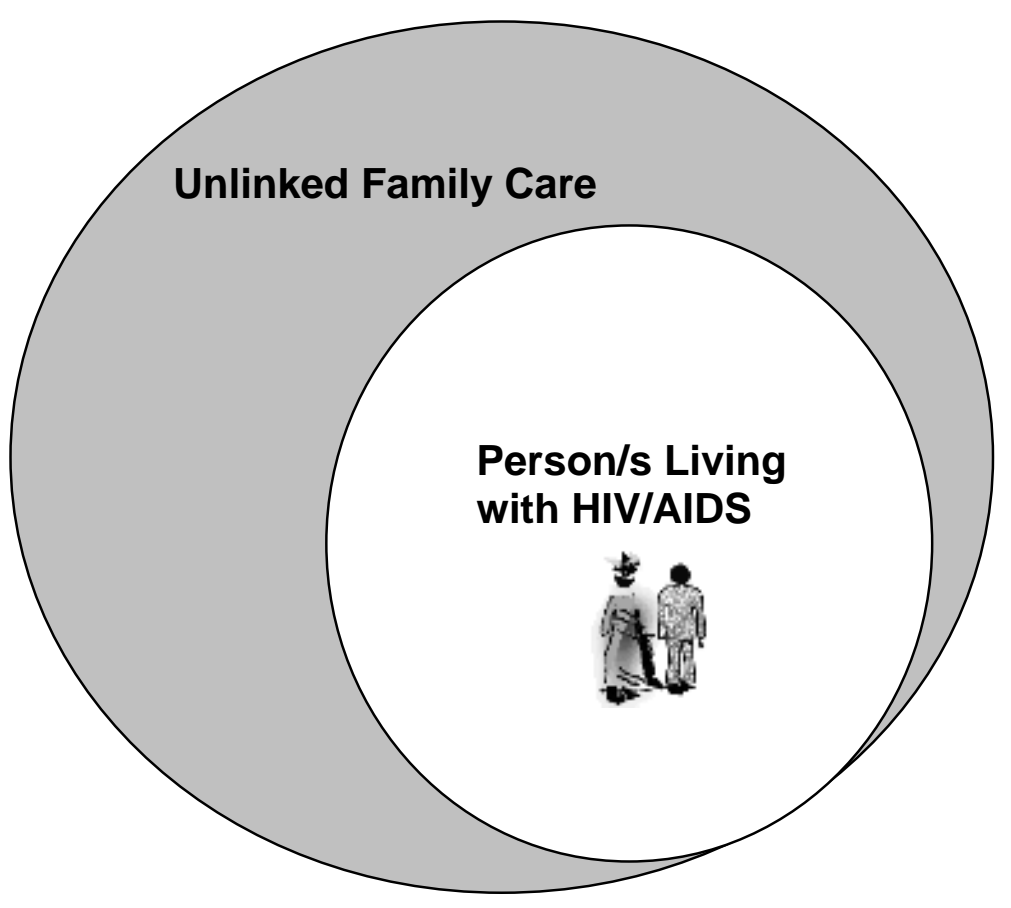

\section{Situation 1:}

This diagram depicts the situation prevailing in the vast majority of AIDS-affected households. The gray circle represents the large universe of care provided by family members within the household. The figures in the white circle represent household members living with HIV and AIDS, and the circle itself represents the large proportion of the household care economy that is devoted to the care of those living with HIV and AIDS.

This household type is unlinked to any formal care program, and has little access to health care facilities. Those living with HIV/AIDS in the home and/or their principle carers are not likely to have obtained a formal HIV diagnosis. For this reason, they may be obtaining medicines and various remedies for symptoms from traditional healers, herbalists, and local pharmacies or drug shops. But the family in this situation does not have the resources of time or money to attend formal health care services regularly. 


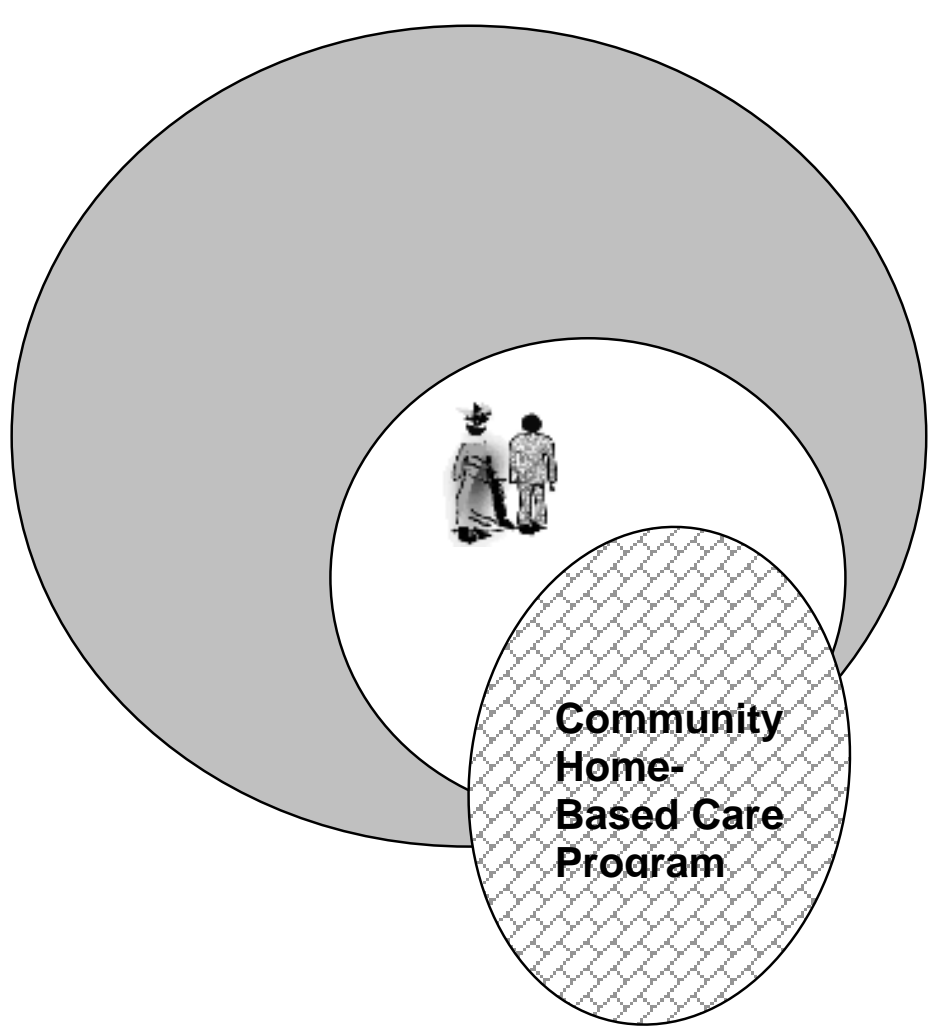

\section{Situation 2:}

The household member living with HIV/AIDS is receiving some support from a CHBC program. By taking on some care tasks, the CHBC program is alleviating some of the care burden borne by the family. Although they may be getting some clinical care from the CHBC program, they may not be accessing formal facility-based health services due to lack of resources, lack of trust in the system, or a range of other reasons, including gender issues. The types of services being provided by CHBC programs in this scenario may include:

- Spiritual and emotional support.

- Help with custodial tasks such as washing bed sheets and clothes of PLHA.

- Help with hand-feeding.

- Help bathing the PLHA.

- Other minor nursing duties.

- Provision of some medications and treatment for symptoms and uncomplicated opportunistic infections. 


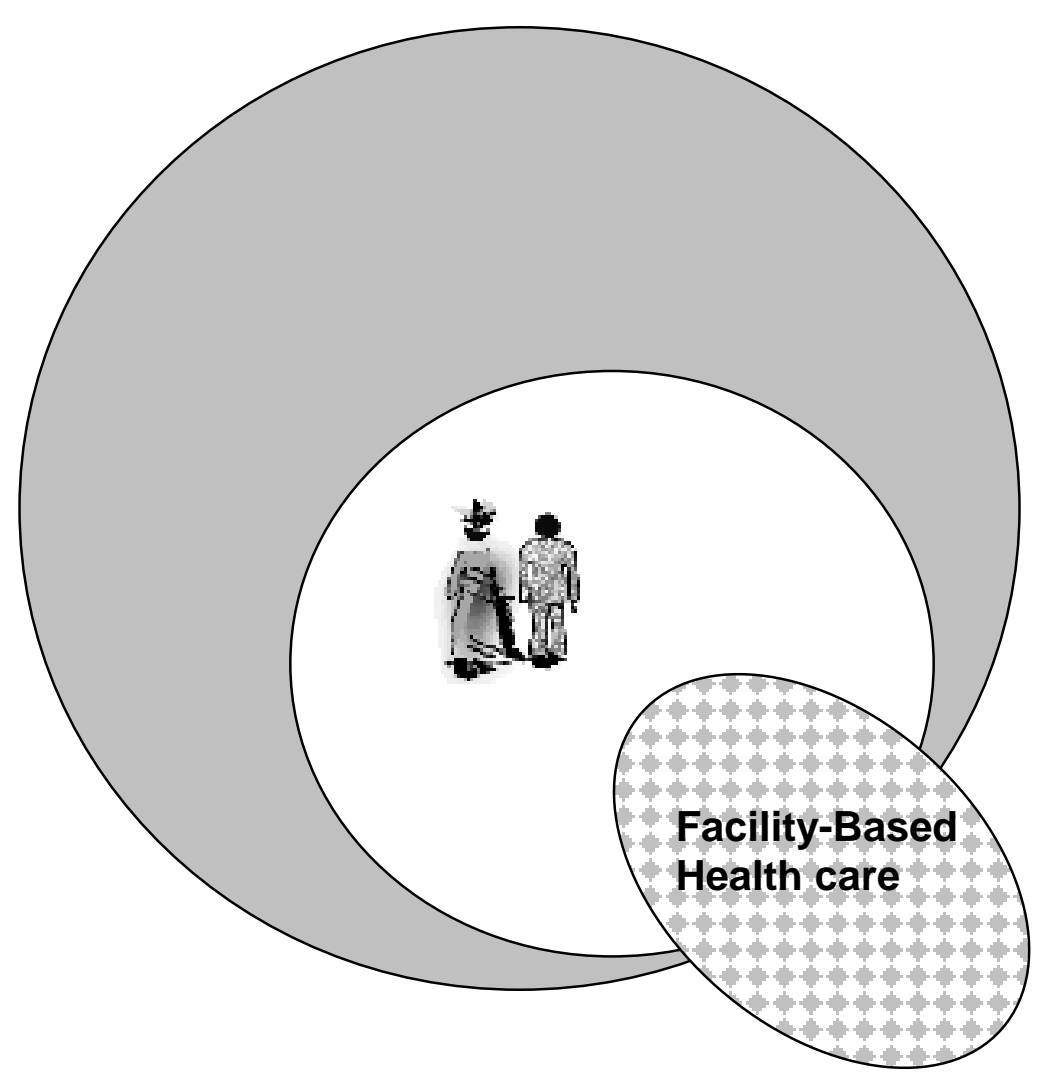

\section{Situation 3:}

In this situation, the household member infected with HIV is obtaining access to some facility-based health care (represented by the checkered oval). Note the household is not directly benefiting from this care (the checkered oval does not overlap with the gray). In fact the overall household burden has grown somewhat due to the financial and opportunity costs of formal health care.

The types of clinical care provided in facilities might include:

- Treatment for opportunistic infections (e.g. TB, trush, pneumonia, etc).

- Treatment for other sexually transmitted diseases.

- Pain relief.

- HIV counseling and testing. 


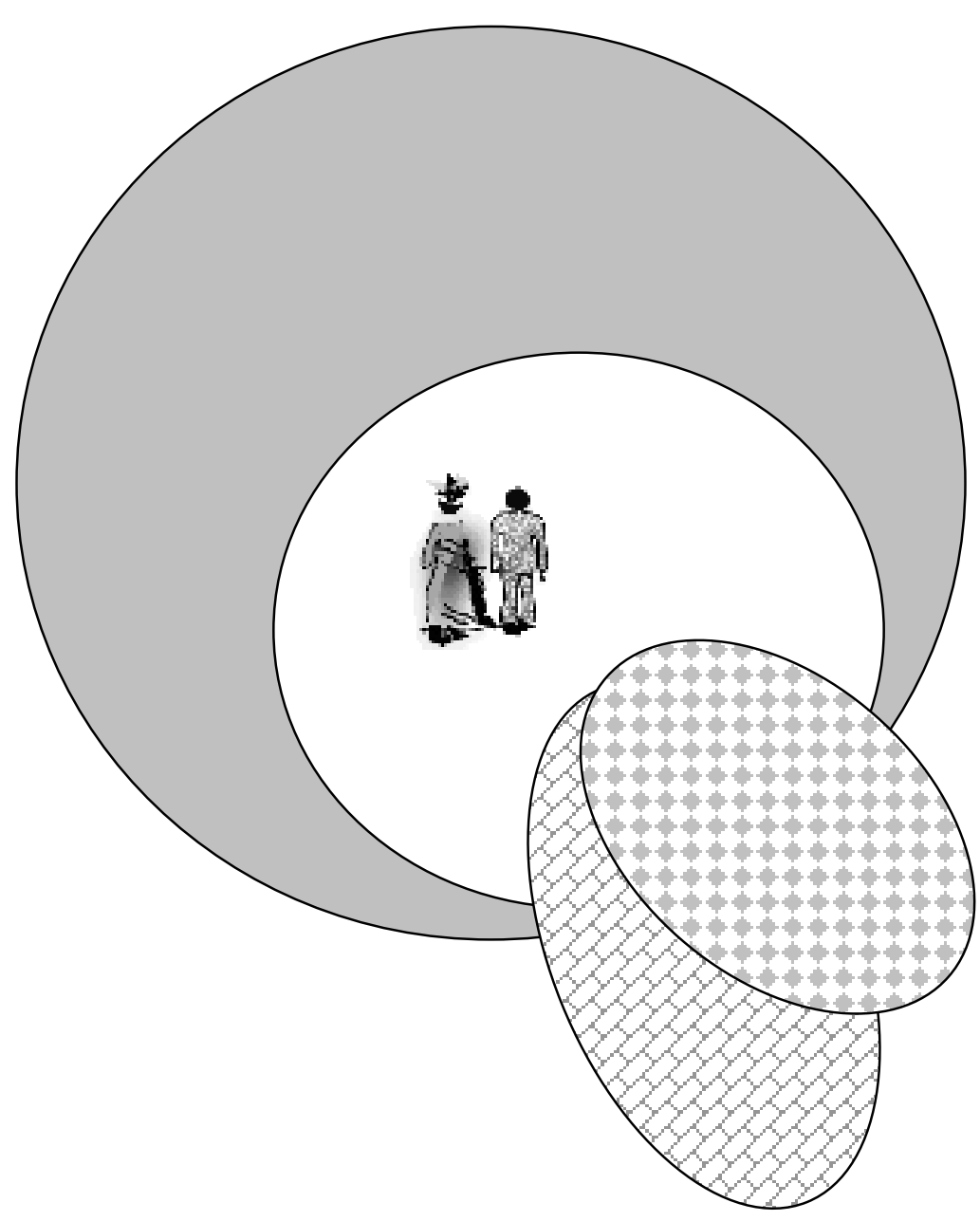

\section{Situation 4:}

The household represented here is linked to a community home-based care program, and the person living with HIV is receiving some clinical care from facility-based health services. The $\mathrm{CHBC}$ program in this scenario is also linked to formal health sector facilities, so may be better able to be provide clinical inputs. However, the program does not have a conscious family support component. The person living with HIV/AIDS In this situation is getting the benefit of improved care, but the household and household carers are not benefitting as much as they might be if the $\mathrm{CHBC}$ program and the formal health sector services were purposively addressing their needs. 


\section{Hgrizons}

\section{Challenges Faced by Unlinked Family Care Providers}

There are a great many challenges facing unlinked carers, ranging from burn-out and impoverishment to increased vulnerability to illness. Unlinked care providers receive no training, no support from formal programs, and no concrete inputs such as gloves or medication. Adult carers as well as children lack information about the disease they are managing or what to expect over time. Indeed, many do not know that the loved one in their care has AIDS. In addition, due to HIV/AIDS-related stigma, caregivers may be closed off from social support at the time they need it most. Neglect of those living with HIV and AIDS can sometimes result from a carer becoming exhausted and having run out of options. This last outcome can be devastating for all involved, not least the carer herself, who might otherwise derive great satisfaction, improved self-esteem, and approbation from the community for being a "successful" carer.

\section{Emotional and physical burdens}

Akinkola's recent study (2003) is one of very few that specifically assesses the physical and psychosocial consequences of providing care for people living with HIV and AIDS, although these were also touched upon by Hong et al. (2004). Akinkola notes that physical consequences include sudden and recurring head and body aches, and fatigue and muscle strain from lifting patients and other chores associated with care-giving. At the same time, caregivers in this study tended to downplay these physical impacts and delayed seeking health care-prioritizing instead the needs of the person for whom they were caring. Emotional stresses were also felt, particularly as a patient's health deteriorated dramatically. Carers in this study described their feelings of despair and "impotence in the face of the care recipient's imminent death" (Akinkola 2004). These feelings could be compounded for those caregivers who are, or who suspect they are, also living with HIV, as they observe and cope with the severe, sometimes horrific symptoms of AIDS-anticipating as they must their own eventual illness and death.

These caregivers need support in the form of education, information, psychosocial support and counseling. Caregivers need education on the basic facts on HIV/AIDS and the ever-changing face of AIDS. They also need education on the various feelings they can expect to go through and how to handle these. Most importantly, perhaps, they need those inputs, such as gloves, water, and respite that will enable them to carry out their care work effectively and safely.

\section{Challenges to women in their nurturing roles}

HIV/AIDS poses a number of important challenges to women in their nurturing roles. Clearly, being producers of household health (Berman et al. 1994) is a vital social role played by women in many countries, and women do experience improved self-esteem and approval by society for their care-providing skills. However the material and psychological demands placed on them in the context of this epidemic differ dramatically from those required under normal, or pre-epidemic, circumstances. While many women embrace their care-giving roles, they are increasingly being expected to perform these roles under conditions of ever increasing poverty and constraint. With 
fewer resources at their disposal, women are being expected to do more. Where they were once able to divide their time between a wide range of tasks, they are now having to make impossible choices between, for example, spending necessary time and money on agriculture to produce food for the family or carrying a spouse to a pit latrine. It is important to note that many of these women will take on additional caring work, even beyond what they are expected to do in their own household, as volunteers for home-based care programs.

A further issue that requires consideration is that many women carers are themselves living with $\mathrm{HIV}^{6}$, and yet there may be no one else present in the household to look after them when they too fall ill. Although the role of care would typically fall to another female relative-usually the mother-not all mothers are willing or able to care for their sick adult daughters (Livingston 2003).

And finally, a woman's role as care-provider does not end with death of a husband, child, or sibling, as the care of orphans will often fall to grandmothers and aunts ${ }^{7}$ who may or may not be able or willing to assume this responsibility. It is notable that the potential impact of HIV/AIDScaring on older women was flagged as early as 1988 (Beer et al. 1988).

Women caregivers are not necessarily isolated in their caring roles, and Barnett and Blaikie (1992) document a range of ways that affected women help each other. Neighbor women, they note, tend to support each other in their care-giving roles, including giving each other breaks and providing emotional support. The Masaka women interviewed reported that the various informal "counseling sessions" that women provided each other in the course of everyday life (for example when collecting water or fuel or sharing a cup of tea) were vital for their well-being and ability to continue caring for the sick in their homes. These women said that one of their greatest needs was for more safe public places for women to meet together, just to talk and share experiences.

These examples of the challenges faced by women in fulfilling their roles as nurturers in their families indicate that it is important not to take women's caring for granted but to accord it due value, and to provide these women the means necessary to carry out this work effectively and with dignity.

\section{Traditional "safety nets" threatened}

The strength of the "African extended family" has been commented on widely and evoked in any number of contexts as a support to the process of "development," as the following quote suggests:

"In rural Africa, the extended family and clan assume the responsibility for all services for their members, whether social or economic. People live in closely organized groups, and willingly accept communal obligations for mutual support... The sick, aged and children are all cared for by the extended family" (Shawky 1972, pp. 4-5, quoted in Seeley et al. 1993: 117).

\footnotetext{
${ }^{6}$ www.who.in/inf-fs/en/fact242.html

${ }^{7} \mathrm{http}$ ://www.eldis.org/gender/dossiers/socimpact.htm
} 


\section{Hgrizons}

There is evidence that this has been the case, historically at least, in some settings and for some individuals. As Ankrah (1991) noted over a decade ago: "[F] ew Africans are without the extended family as a 'resource' when AIDS strikes." Likewise, Taylor et al. (1996) cite a number of authors making similar claims - for example, McGrath et al. (1993) in relation to Uganda, and Caldwell et al. (1993) referring to Ghana. More recently, Foster (2002a) notes the extraordinary resilience of families in Zimbabwe, their ability to survive crises, and the fact that they continue to find ways to effectively support, console and nurture their sick members and to absorb children orphaned by the epidemic.

Yet from the earliest days of the epidemic, concerns were being voiced that this resource would become over-exploited. As Carballo and Carael noted in 1988, for example:

"There are again anecdotal reports... that families may not be able to deal as spontaneously with AIDS as they have been with other health problems, and that the traditional reliance on extended kin systems may not be as warranted as it was in previous crisis situations" (Carballo and Carael 1988:87).

PANOS make a similar point a few years later:

"Some doctors and social scientists in the south are concerned that reliance on the extended family is overplayed...they argue that for many people the extended family as a safety net can be no more than a myth" (PANOS 1990: 61).

In response to these concerns, observational studies began to explore the impact of HIV/AIDS at the household level. One such study found that it was unrealistic-even at that relatively early stage of the epidemic - to expect extended families to provide the full range of necessary care services to people living with HIV/AIDS, that extended families in that setting were already unable in an increasing number of cases to provide assistance, and that many were in fact unwilling to do so (Seeley et al. 1993).

Others concur:

"It is evident that the relatives and friends are valuable resources in times of need. Research has, however, questioned the notion that the extended family is a resource to be relied upon at all times, and has suggested that families may not be able to deal with AIDS as they have with other health problems.... We must therefore question whether the traditional reliance on extended kin systems will address the needs of HIV/AIDS patients and their informal carers" (Taylor et al. 1996:55).

Seeley et al. (1993) conclude by asserting that "blanket statements about the role of the extended family in Africa as a safety net need to be questioned and assumptions that the extended family will be ready and able to assist sick members, treated with caution." The extended family, they quip, is a "safety net with holes." 
If the ongoing strength and resilience of the "extended family" was being questioned, so too was the conventional definition of "the household." According to Foster (2002b), households are often thought of as "a group of people, living together, who are usually economically interdependent," a definition that implies a certain degree of moral, physical/geographical and material coherence and autonomy of one household vis á vis others. It is increasingly apparent, however, that households are actually more dynamic than this definition implies, and that these social units are undergoing important (but still poorly understood) changes, particularly in highly HIV-affected communities. Barnett and Blaikie (1992) argue, for example, that part of adaptation to AIDS is to change household composition: households affected by AIDS periodically breakup and members disperse to other households. As prime-aged adults die, new forms of household develop including:

- Households headed by elderly people caring for young children.

- Large households composed of or linked to a number of unrelated fostered or orphaned children.

- Cluster foster care-where groups of children are cared for formally or informally by neighboring adult.

- Households inhabited by a single, childless adult woman or man, or even individual children.

Because the impact of HIV/AIDS accumulates over time and AIDS deaths tend to cluster in families, it is likely that one or more members of these newly formed household units will in turn become sick from HIV infection, and so some means of caring for the infected person must be found when they fall ill. Some affected households are trying to adapt by changing their composition, where clusters of households start to operate together to pursue a common livelihood strategy in the face of HIV/AIDS care needs and adult death (Barnett and Whiteside 2002:13). In other cases, households dissolve altogether. According to Mutangadura's study of 215 households in Manicaland, Zimbabwe, 65 percent of the households where the deceased adult female used to live before her death were reported to be no longer in existence in both urban and rural sites (Mutangadura, 2000).

Thus, the dynamism inherent in household structures in the context of mature HIV epidemics may pose particular challenges to programs designed with a more static, autonomous household in mind, as Eberstein et al. (1988: 176) remind us:

“... adopting a family (ties of kinship) or household (co-residence without regard to kinship ties) frame of reference adds an important perspective to assessing the social consequences of AIDS" (Eberstein et al. 1988: 176).

\section{Challenges to Community Support}

As with the extended family, some have remarked that communities are not always able or willing to fill the "care gap" as they may have before AIDS, and some caution has been urged against depending too fully on this resource in AIDS programming. Osborne (1996: S65) makes the point that not long ago in Zambia, "the whole community was 'family' with every child being a son or 


\section{Hgrizons}

daughter of the community. Had HIV/AIDS come on the scene in that era, communities would certainly have coped better than they are doing now" (see also Carballo and Carael 1988; Parkin and Nyamweya 1986). The implication here is that the introduction of nuclear family structures has broken down the community feeling that used to prevail, resulting in disparate communities.

More recently, Russel and Schneider (2000:10) point out that in South Africa, the concept of "community" needs to be seen in the light of that country's political and economic history-during which "families were systematically disrupted by migrant labor policies, community removals, political conflict and urbanization." They posit that for these reasons, South Africa may be at a disadvantage in the replication of "community-based" programs that have succeeded elsewhere. While South Africa's history is certainly unique, other countries in the region may have experienced similar disruptions. Issues of migration, urbanization and conflict feature in many countries of the world and intersect with devastating HIV/AIDS epidemics in many of them.

There is a growing recognition of the importance of social capital in maintaining communities, and volunteering is viewed as a core component of social capital (Onyx and Leonard 2002). In some circumstances, assumptions about the "community" have resulted in an over-reliance on volunteerism and volunteers. Recent studies have indicated that volunteerism cannot be taken for granted, and that there is a need to provide incentives, material help and skills for this strategy to work effectively (Jain 2003; AED-USAID 2003; UNAIDS 2000a). This is the case not least because the people who are volunteering in community home-based programs are often the principal care providers for people living with HIV and AIDS in their own homes.

Social capital一the social interactions that are "invested" in community life and can be drawn upon in the form of support from community members-is rapidly diminishing in communities affected by HIV/AIDS. In some places, the total absence of social capital is resulting in increasing numbers of young child headed-households. Orphans are left with care responsibilities for younger siblings and are forced to find sources of cash income to survive.

One of the important "holes" in the assumed family/community safety net was and continues to be the stigma that is associated with HIV/AIDS. In a study in South Africa (Steinberg et al. 2002), only 35 percent of people living with HIV reported having experienced a supportive response from their community, with one in ten recounting hostility and rejection, including outright

discrimination. HIV/AIDS-related stigma is a complex phenomenon that has received an increasing amount of attention - and so greater understanding - in recent years (e.g., Nyblade et al. 2003; Hong et al. 2004; Parker and Aggleton 2002). Yet the role stigma plays in shaping the care and or lack of care available to those living with the virus is not new, and this stigma has a vital bearing on home- and community-based care, seriously challenging assumptions about the caring resource of the family and community.

In order to understand the impact of stigma, it is first important to understand why stigma occurs. Although many people are not aware that they are HIV-positive early on in their disease, and others who know may not disclose this information, as the infection matures their HIV status will become increasingly visible, and so increasingly public. These signs of HIV disease can include fungal infections and lesions on the skin and mouth, bacterial infections causing diarrhea and vomiting, 
loss of weight, and tuberculosis. These symptoms will necessarily cause anxiety and fear as well as physical discomfort for the person who is experiencing them, but at the same time can cause family members to feel angry and/or repulsed. Thus, at the point when they most require care, love and support-and sometimes even help with the some of life's most basic and private functions such as eating, using the toilet, and staying clean-people living with HIV/AIDS may experience instead shock, anger and rejection. This type of reaction by family members and friends may stem from fear (beliefs about the ease of casual transmission are a common source of stigma).

Studies have shown that stigma may also stem from the belief that the person "deserves what he/she got" (moral judgments are also a key source of stigma); or anger and a sense of betrayal (the belief that the person living with HIV had "outside" relationships) (Nyblade et al. 2003). The high prevalence of fear, stigma and shame associated with HIV/AIDS are often exacerbated by the lack of knowledge and experience about "what to do" when someone falls ill with AIDS-related illnesses, what kind of care they need, what to expect over the course of the illness, and what help is available. Additionally, exposure to and handling of another's body by a member of the family or community can be both taboo and unfamiliar. Whatever its cause, stigma experienced by people living with HIV/AIDS in the home and community is widely reported as being the most hurtful and debilitating form of stigma (e.g. Procaare 2001; Nyblade et al. 2003).

In addition to understanding why stigma occurs, it is also important to know what forms stigma takes in the home and community. Stigma is manifested in a wide variety of ways from what may seem the most benign forms-e.g., keeping the belongings, dishes and clothes of the infected family member separate from the others- to the most malignant forms of neglect and even abuse. A study from Vietnam showed that stigma related to fear of infection sometimes led family members to take extreme and unnecessary precautions, such as minimizing contact between the person living with HIV and AIDS and other family members, particularly (but not only) small children; separating the belongings of the person living with HIV and AIDS; and designating specific eating utensils, towels and bed linens for the sole use of that family member. It is important to note that many family and community members will not see these types of reaction as stigmatizing, but protective (e.g. Hong et al. 2004). Nonetheless, sometimes this fear impeded provision of optimal care, as the following quote of a Vietnamese woman caring for her brother with HIV/AIDS illustrates:

"Since I found out about his infection, I never touch his body... The family has to provide care; the family cannot abandon him, cannot neglect him. Despite anger, the family has to strive hard, but it is so frightening. If the disease becomes more serious, I cannot give care anymore because it is too scary. I don't know very much about how to provide care-I know only to wear gloves. So when his illness becomes more severe, I cannot care for him any more, I will have to withdraw, I cannot care for him." (Hong et al. 2004:26).

In a more extreme case a number of people living with HIV/AIDS in South Africa reported that respondents were sometimes "locked up" or "locked out" by family members (Russel and Schneider 2000). The first refers to situations in which people living with HIV/AIDS are kept in a locked room, hidden away from community view and isolated from social interaction. Being "locked out" refers to individuals living with HIV/AIDS who are rejected by their families and literally turned out on the street. In their study of family care provision for people living with 


\section{Hgrizons}

HIV/AIDS in Uganda, Seeley et al. (1993:119) found that family members would sometimes limit or deny care because of stigma. In three out of the 15 cases studied, the researchers found that the person with HIV infection had been ridiculed by relatives who blamed her (in all cases the person in question was a woman) for her condition.

Less overt but nonetheless painful forms of stigma may include the withdrawal of economic or material support from the infected family member-a reaction particularly common in poor households and where the person living with HIV/AIDS is not an earning member of the household (Procaare 2001). Infected family members may be denied treatment out of the belief that they "will die anyway" so that the expenditure would be wasted.

Gender and stigma interact in painful ways in the care of people living with HIV/AIDS. Although it is not always the case, often when a woman's husband dies of AIDS and she herself becomes ill, the husband's family (who may blame her for "bringing" the illness) will send her back to her natal home to be cared for and to die. This may have important repercussions for her: her fate will often depend on whether or not she managed to maintain close relations with her own kin, and whether they are in a position to take on one-or maybe more-additional dependent household members. In addition, many of these women will lose access to any inheritance they may have had rights to, and many have their children taken away from them (FAO 2003, 2002).

These are but a few of the many examples of the impact of stigma on home and community caring-and they illustrate why it may be ill-advised to assume too much about the "caring family" or "caring community" when setting up formal programs to support home based care. The establishment of such programs must go hand in hand with stigma reduction activities. Opening home-care programs to all long-term chronically ill people in the community has been noted by many of those approached for information for this paper as a useful beginning step. 


\section{The Health Sector Response}

"The moral and practical imperatives of providing care for those whose lives have been-directly or indirectly—sabotaged by [HIV/AIDS], have reached unprecedented levels. In South Africa we have moved from an HIV epidemic to an AIDS epidemic. Inevitably, the growing number of people falling desperately ill escalates, and with this comes the unavoidable need to interrogate the issues that cluster around care" (Trengrove-Jones 2001:9).

Partly because there continues to be no medical magic bullet to cure HIV and because of the natural history of the disease, the emphasis of HIV/AIDS policies and programs has, from the earliest days of the epidemic, been on prevention. Yet as the above quote implies, what was once a relatively "silent HIV epidemic, has become a visible AIDS epidemic" (Russel and Schneider 2000), and out of this visibility an awareness is slowly emerging at national and international levels of the importance of care and an international "care agenda." As one observer remarked, however, the emergence of the care agenda has been reactive rather than the more proactive approach that was taken around prevention. ${ }^{8}$ And as a reaction, it came late- a programmatic approach to "care and support" did not emerge until the mid-1990s. Yet prior to this time it had already become apparent that a substantial "care gap" (Russel and Schneider 2000; Blinkhoff et al. 1999) existed. Although this was met with some responses, the efforts tended to be small in scale, haphazard and unsystematic. Indeed, a bird's-eye view of the home-based care "landscape" would reveal a crazyquilt of ad hoc, micro-level responses, some of which may be effective in meeting the care needs of those affected, and some of which may not-the coverage and effectiveness of the majority of these programs remains unknown, as very few have the resources or capacity to monitor or evaluate their activities. Meanwhile, the formal health care sectors of the most hard-hit countries, already buckling under the combined strains of structural adjustment and health sector reforms, have been simply unable to cope with the increased demands being placed on them by the epidemic. Therefore, throughout the epidemic, the need for care has been keenly felt-and attempted to be met-in the homes of those directly affected, usually without the benefit of external assistance. Yet, this experience remained largely taken for granted, undocumented and unaccounted for within the "care agenda." This continues to be the case in the current context, which is marked by the increasing availability of effective medical treatment for people living with HIV and AIDS. There is some concern, in fact, that efforts to make antiretroviral treatment available to the many millions who could benefit from its use will overshadow and diminish interest in supporting the further development and expansion of the care agenda. If so, this could have profound implications for many millions sick and dying of AIDS and their carers, for whom such life-enhancing therapies remain out of reach.

\footnotetext{
${ }^{8}$ Interview with Horizons Program staff member, Washington, D.C., July 2003
} 


\section{Hgrizons}

\section{The I mpact of HIV and AI DS on Hospitals and the Health Care System}

HIV/AIDS is a progressive disease, and the health care needs of those infected change over time. On an individual level a person can remain healthy with HIV infection for years before experiencing periodic and increasingly severe and debilitating bouts of illness, ranging from skin infections, diarrhea and other opportunistic infections such as tuberculosis, as well as some forms of cancer. The care needs of people living with HIV will change accordingly and range from basic "no frills" clinical treatment for opportunistic infections to day-to-day palliative care and support ${ }^{9}$.

On a population level, as an HIV epidemic matures, there will be increasing numbers of people experiencing these effects over time, leading to an overall increase in morbidity and mortality, with subsequent impacts on every aspect of a community's functioning. The cumulative effects of increasing HIV sero-prevalence in highly affected countries results in unprecedented demands being placed on already under-resourced health care services-services which have been further weakened by health sector reform and structural adjustment programs (see De Jong 2003). It is commonly reported, for example, that $50-70$ percent of all hospital beds in many affected countries are being occupied by people with HIV infection (see Haacker 2001; Carballo and Careal 1988; Osborne 1996; Msobi and Msumi 2000; Guiness et al. 2002). One project recently reported that if all AIDS patients in Tanzania were treated in public health facilities and if sufficient drugs were available for this purpose, treatment would absorb roughly half of the entire public health budget (Msobi and Msumi 2000). In some countries the problem is further compounded by high absenteeism and increased death rates among hospital staff (Buvé et al. 1994; Foster 1995; Foster 1994). ${ }^{10}$

Despite the heavy demands being placed on these weak formal health care services, however, it is important to note that this burden reflects only a portion of the total number of people needing care for HIV-related illness. As those obtaining an HIV diagnosis are in the minority of the total number infected (UNAIDS 2002), most people living with HIV infection will seek symptomatic relief from pharmacies or treatment from out-patient clinics. As the chronic nature of the illness becomes apparent, many will seek treatment from traditional healers (Osborne 1996; Ankrah 1991; Carballo and Careal 1988; Carswell 1988). Those who know or suspect that they have HIV might also be reluctant to obtain care in the public health sector for a variety of reasons including stigma, fear of disrespectful treatment from health center staff, or merely from their awareness that there is no cure. And many, many people living in poor countries have, in any case, inadequate access to existing services. Therefore, the majority of those affected remain in the community without the

\footnotetext{
${ }^{9}$ Gilks et al. 1998 provide a comprehensive overview of the clinical care needs associated with the different stages of infection.

${ }^{10}$ It bears noting that these problems persist to the present day. A recent UNAIDS Fact Sheet reports that "in Africa, where two-thirds of the world's HIV-positive people live, health-care systems, which were already weak and under-financed before the advent of AIDS, are now buckling under the added strain of millions of new patients. In many places, facilities for diagnosis are inadequate and drug supplies are erratic, even for HIV-related conditions that are easy to diagnose and inexpensive to treat" (UNAIDS Fact Sheet. "Access to HIV Treatment and Care" July 2003).
} 
benefit of formally organized health care provision and are being cared for by family members at home.

\section{Shifting Clinical Care to the Home and Community}

Around the mid to late 1990s, programmers and policy-makers, realizing that public sector provision was going to be unable to manage AIDS-related morbidity, began considering ways to shift the locus of clinical care from the health services to the community. Initial efforts revolved around a principle of hospital-based outreach, whereby hospital staff traveled directly to patients' homes to provide care. As Osborne et al. (1997: S138) explain: "The argument for the hospitalinitiated home-care models was that, given the limited treatment available in hospital for many AIDS patients, it was neither in the health services' nor the patients' interests for them to be in hospital. Instead it was better to care for patients at home, looked after by their own families with dignity." Not surprisingly, however, these programs were found to be time-consuming and expensive, especially in rural areas (Hansen et al. 1998; Chela 1995).

In many communities, meanwhile, new NGOs were sprouting up and existing groups mobilized to provide support to families affected by the disease in an effort to fill the "care gap" left by the retreating public sector. These groups were largely unable to provide clinical inputs (with the exception of efforts mobilized through faith-based hospitals), instead providing a range of care and support services to affected persons and families including spiritual and emotional support, assistance with funeral expenses and some basic nursing care. Yet given their limited resources, and in the face of the enormity of the impacts being experienced, many of these community initiatives struggled, their networks and strategies often only able to reach a small segment of the affected population, especially in high prevalence countries. An important exception is the program started in 1991 by the Catholic Diocese of Ndola in Zambia's Copperbelt Province. By 1998, a rapidly expanded program had evolved, reaching 23 townships with a total population of 400,000. With reasonable cost, the program achieved a high coverage of its target population and succeeded in integrating TB control into home-based care. Central to this program is the role played by 500 volunteers, mainly women, who assist their neighbors to cope with the dual epidemic. (See Blinkhoff et al. 1999 for a full discussion of this program.)

In response to the growing recognition that a more programmatic approach to care for persons living with HIV/AIDS was needed to assist and coordinate the many ongoing responses, the WHO, in consultation with a wide group of experts, developed a framework for "Comprehensive Care Across a Continuum" (van Praag 1995; Osborne 1996)-later known more simply as the "Care Continuum" (WHO 2000c). According to Osborne (1996: S62), "the continuum contains a range of comprehensive services, including counseling and testing, clinical management, nursing care and community-based social support. The provision of care extends from the individual/home to the hospital, through various levels of care linked with discharge planning and referral networks, and back to the individual/home." The intent of this model was to promote, create and sustain a holistic approach to "care and support" for persons living with HIV/AIDS. The framework locates the person living with HIV/AIDS at the center of a wide range of actors who are dynamically linked. The entry point to the "continuum" is voluntary counseling and testing for HIV. "Home Care" is 


\section{Hgrizons}

one element of this broader system of care provision, and it is an element perceived to be particularly relevant and important in resource-constrained settings (e.g. Osborne 1996; Osborne et al. 1997; Gilks et al. 1998; WHO and UNAIDS various).

\section{Figure 2 The Comprehensive Continuum of Care} Source: WHO 2000c. Key Elements in Care, Treatment \& Support

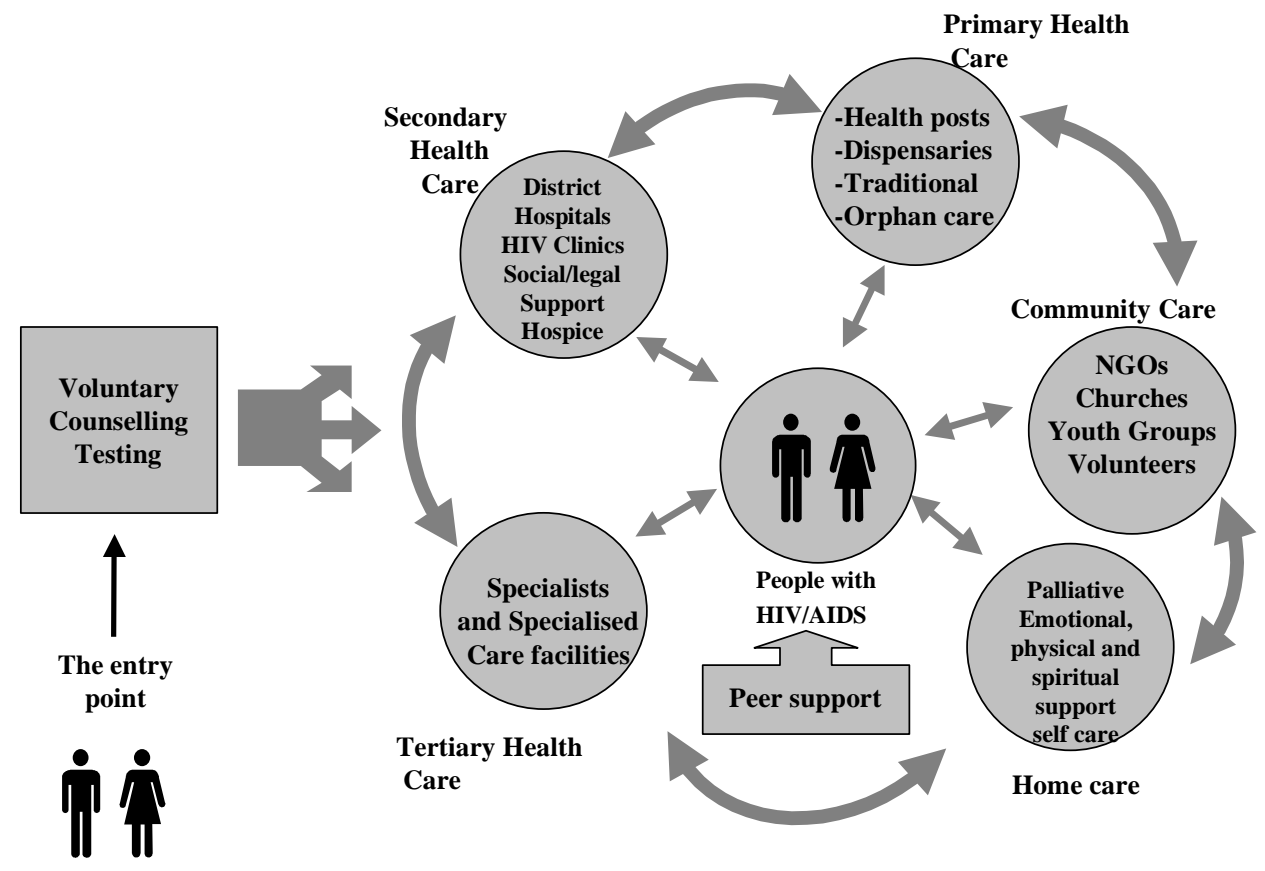

\section{The Comprehensive Continuum of Care}

The "care continuum" is an important advance in development of an agenda around care at the international level (see Figure 2). It provides a framework that governments can follow to ensure that they are putting into place some of the key components enabling those individuals who obtain an HIV diagnosis to receive clinical and non-clinical care, and it attempts to illustrate the need to create linkages between the various care domains. Viewed through the "care economy" lens, and taking into account the prevalence of unlinked care, however, a number of important areas for further development emerge:

1. The model assumes that the person needing care will have obtained an HIV/AIDS diagnosis despite the fact that the vast majority of people living with HIV and AIDS do not have access to, or chose not to access VCT services; 
2. Although "home care" and "community care" feature in the continuum, the focus remains on formal health sector interventions, failing to account for challenges to access posed by factors such as poverty and gender;

3. All the steps on the continuum except "peer support" and "home care" indicate who will provide care, while the "home care" domain indicates, rather, what type of care will be provided, thus masking the differential impacts on individuals of providing care in the household;

4. The linkage mechanisms remain poorly defined. The ways in which any given individual moves "across" the continuum are not apparent, and the "peer support" domain is completely unlinked to the rest of the continuum.

Despite these gaps, Gilks et al. (1998) report that the continuum of care has been strongly promoted by the WHO and member states and has led to the growing recognition of the crucial role community-based activities and initiatives play in enabling both carers and PLHA to cope with the burden of ill-health and suffering caused by HIV/AIDS.

\section{The Community Home-Based Care Movement}

As noted above, a programmatic approach to the long-term care needs of people living with HIV/AIDS did not emerge until the mid-1990s. However it is clear that families, households and communities had earlier begun to respond to the crisis. The core of this response was and remains within affected households themselves-what we have referred to as the "unlinked" domain of care. Outside this core are a wide variety of responses which initially built on pre-existing, or "indigenous," mechanisms for coping with crisis and disaster (Barnett and Blaikie 1992; Foster 2002a), and have included faith-based and other community groups. Indeed, many countries witnessed something of an explosion of small-scale programs that were, for the most part, underresourced and many times unlinked to broader sources of support, skills, supplies or training. Blinkhoff et al. (1999), for example, report that in Zambia, where the concept of home-based care was actively promoted by the Churches Medical Association and the Ministry of Health from the late 1980 s, there were 100 formally established home-based care programs by 1996 . Many of these programs relied on the time and support of volunteers (both in the administration and implementation) who had little time (nor necessarily the expertise or experience) to design, document or evaluate their programs, much less to seek outside support.

Proponents of the idea of care in the community emphasized the benefits of home care (here meaning care provided in the home by trained professionals or volunteers) for both patients and their families. One study (WHO and Zambian MoH, 1994-cited in Blinkhoff et al. 1999) found that 90 percent of patients and families preferred home-based to hospital care. The benefits of home-care (thus defined) are discussed in various sources (Gilks et al. 1998; Blinkhoff et al. 1999; Osborne et al. 1997; Olenja 1999). These can be grouped under benefits for the people living with HIV/AIDS, the family and the health care system. They include: 


\section{Hgrizons}

For the people living with HIV/AIDS

- The sick are comforted by being in their own homes, surrounded by their loved ones.

- Nurturing and flexible basic care is best given at home.

- The sick are able to undertake productive activities and contribute to the household as their symptoms are relieved.

- $\quad$ HIV-positive people can secure support, for themselves and their family members, by volunteering with AIDS service organizations.

- Family support for the sick person is strengthened (assuming the burden of care is being alleviated by an outside home-care provider).

- Exposure to other infectious diseases in hospital settings is minimized.

\section{For the family}

- Relatives are able to continue other duties alongside their care-giving work, which they would be unable to do if they were assisting the patient in hospital.

- Home care linked to a program can be an effective entry point to programs supporting survivors of the sick person, such as the widowed spouse and orphaned children.

- Home care linked to a program offers opportunities for educating families and communities about HIV prevention and can help de-stigmatize HIV/AIDS and associated infections, such as tuberculosis.

- Home-care linked to a program decreases isolation of family and person with HIV/AIDS.

- Home-care is usually less expensive for families than hospital care for the following (assumed) reasons:

a. Relatives do not have to take time off productive work to accompany the ill person to hospital.

b. Relatives do not have to pay treatment and other in-patient costs.

c. No transport costs are incurred.

\section{For the community and volunteer workers}

- Community members who become volunteer workers gain skills and contacts that will make them employable.

- Volunteer workers are trained and recognized by reputable community and government organizations.

- Volunteer workers gain a sense of meaning and respect through their altruistic offering of community services.

\section{For the health care system}

- Governmental clinics and hospitals can keep patient admissions down.

- The costs of health services and hospitalizations will be lowered.

- Pressures on clinic and hospital staff are relieved, enabling them to serve other clients.

The explosion of volunteer and community-based programs in affected communities has, for the most part, been "rather poorly documented" (Barnett and Whiteside 2002) and has been characterized as "unsystematic and needs-based" (WHO 2002b). In real terms, home-based care coverage in Africa remains low, and most people living with HIV/AIDS continue to be cared for in their homes by members of their own kin network, without the benefit of appropriate clinical care 
or the support of outside organizations (Gilks et al. 1998). With a number of notable exceptions (see Blinkhoff et al. 1999), the majority of formal community home-based care programs are small-scale local programs which, in the initial stages, were not systematically designed, implemented, or monitored; they tended to be unconnected with one another with limited opportunities for cross-learning due to overload, competition for resources, and lack of time (see Jackson 2002). Nsutebu et al. (2001) investigated the low coverage of home-based care programs in Africa, using two home-based care projects in Zambia as case studies, and found that one of the main reasons behind this low coverage is the limited involvement of government. These authors argue that governments should at the very least be providing some form of basic home-based care services and/or strengthen support to other institutions providing home-based care (Nsutebu et al. 2001).

In light of these problems, the WHO and other international policy making bodies have, in recent years, attempted to develop guidelines (WHO 2002b) and frameworks (WHO 2002c) to help national planners to create a more ordered response. The policy framework for Community Homebased Care (CHBC) in Resource-Limited Settings is "a systematic approach for policy-makers, senior administrators and government decision-makers to follow in developing the overall policies and guidelines for CHBC" (WHO 2002c:6). Again, the aim of this framework is to create holistic CHBC that would encompass "provision of care," "continuum of care," "education," "supplies and equipment," "staffing," "financing and sustainability," and monitoring and evaluation.

This new "framework," although focused primarily on the health sector and without clear guidance on how to incorporate unlinked home-based care to the formal system, represents an important advance, endeavoring as it does to be practical, flexible and responsive to change over time. However, when viewed through the care economy lens, a number of weaknesses emerge:

1. The framework does not incorporate a gender analysis of programs to assess the extent to which women-as unlinked family carers and/or as volunteers in formal CHBC programs-have access to the resources (including respite) that they need to undertake their caring tasks appropriately, and that the well-being of households in which these women live is not being undermined.

2. Clearly, the resources necessary and needs of close kin to provide adequate care for their loved ones sick and dying of AIDS will be different from those of even the most rudimentary of community-based voluntary care programs. Nevertheless, almost all of the $\mathrm{CHBC}$ models reviewed for this paper aggregated these various types of care together under the CHBC rubric. According to WHO (2002b), for example, CHBC is defined as "any form of care given to ill people in their homes. Such care includes physical, psychosocial, palliative and spiritual activities." Gilks et al. (1998: 76) describe this domain in a similarly inclusive manner, as "any form of care given to sick people in their own homes. It can mean the things people might do to take care of themselves or the care given to them by the family or by health care workers."Although the framework for Community Home Based Care in Resource-Limited Settings recognizes and includes the family as a key partner, the carer as beneficiary remains largely implicit. 


\section{Hgrizons}

Many of the programs predating the policy framework target care for people living with HIV/AIDS in their own communities and more often in their homes. This is because these programs have recognized that:

"Care in the home, and caring for the household and the carers in the household is important because the worst impacts are felt in households and clusters of households. It is here that costs of the disease are borne. It is here that the mitigation interventions have to be located if they are to be cost effective and sustainable. It is here that social reproduction occurs at its deepest level. It is also here that the government and international community have most difficulty responding. Most governments do not recognize the need; those that do do not know how to respond as the scale of home based programming is too small, and the variability in the circumstances is too great to be covered by large programs" (Barnett and Whiteside 2002).

This section has provided an overview of the international policy developments in CHBC. The following section provides a closer look at the types of CHBC programs currently in place in HIVaffected communities.

\section{Types of CHBC Programs}

Many community initiatives are providing support to people living with HIV/AIDS, their families, widows and orphans. Some of these initiatives pre-dated the epidemic, but continue with renewed salience (such as funeral societies, mother's unions, savings clubs). Others have been created anew specifically to offset or mitigate the impact of the epidemic on community members. Many of these initiatives are faith-based, some are "traditional" (e.g. based on locality, ethnicity or kingroup/clan), and all depend upon the compassion of their members and an abiding commitment to preserving or re-establishing the well-being and survival of the community (e.g. locality, ethnic or kin group/clan) as a whole.

Russel and Schneider (2000) indicate that much of the recent literature on community-based care and support comes from sub-Saharan African countries, notably South Africa, Botswana, Zimbabwe, Zambia, Tanzania, Malawi and Uganda. In these countries, systematic efforts have been made to implement and evaluate community-based activities since the late 1980s and include some well-known models such as the Family AIDS Caring Trust (FACT) in Zimbabwe and the AIDS Support Organization (TASO) in Uganda. The types of services provided by the programs include counseling (one-on-one and in support groups); social services (financial, legal and material support); and medical/nursing care (home-based and palliative care). ${ }^{11}$

In a review assessing the community-based care and support programs in South Africa, Russel and Schneider (2000) look into the appropriateness of the services provided in meeting needs, and the challenges encountered to providing quality services. Their review finds that support for people living with HIV/AIDS was very "patchy" and most often lacking. However, in a number of areas

\footnotetext{
${ }^{11}$ For details go to http://www.kznhealth.gov.za/AIDScaresupportprograms.pdf
} 
they saw individual programs emerging to fill the "care gap". Most of these programs tended to be new and functioned with limited support from the outside. With a few exceptions, there were no systematic attempts from provincial or district/local government to accelerate and support the development of these programs.

The activities of these programs focused on people already ill with HIV/AIDS, and within this group, on hospice and home-based care for the very ill and home-bound. Osborne et al. (1997) identify efforts according to the type of organization. Some of these efforts are initiated by local/indigenous community-based organizations, others are launched by faith based groups or NGOs, and a number of these programs are linked to the public health system, international NGOs and donors. Each has advantages and disadvantages, but almost all of these community-based care programs depend on volunteers to some extent to reduce costs and bring care closer to those in need.

Volunteerism is central to the ability of CHBC programs to extend their reach to as many of those in need as possible - or to "close the home-care gap"12 as suggested by Blinkhoff et al. (1999). UNAIDS (2000a) has published a useful case study entitled "Caring for Carers: managing stress in those who care for people with HIV and AIDS." This study explores the motivations behind volunteering (including a sense of religious duty, compassion for others, empathy, and a desire to make a contribution to fight the ravages of AIDS) and the stresses attendant upon this work. A key source of stress identified in this and other studies (e.g. Esu-Williams et al. 2003) was the inability of the volunteer to help families meet their fundamental material needs such as for food and cash. This difficulty highlights the importance of such programs to link more effectively with efforts to underpin household and community stability and well-being, such as microfinance and food security initiatives (to be discussed below).

Table 1, adapted from Osborne et al. (1997), provides an overview of existing CHBC models, offers examples of linked programs, and highlights some of the advantages and disadvantages of each model. The examples provided come from the literature and from our own communications with specific programs. These programs have been included here because they extend their reach to include family caregivers in a range of ways, even though their main focus is providing services for people living with HIV and AIDS. Most of these programs support carers through the provision of information about how to care for someone living with HIV and AIDS and how carers can protect themselves from becoming infected (for example through the use of "universal precautions"). The Ugandan self-help group, A Friend in Need, differs from the others, as it is the only program we were able to identify that is set up by and for family caregivers. Additional case studies highlighting linked CHBC programs appear in Appendix A.

\footnotetext{
${ }^{12}$ The "home care gap" refers to the inability of CHBC programs to reach more than a small proportion of HIV/AIDS patients. By the late 1990s it was decided by members of the Southern African Network of AIDS Service Organizations, that the way to "close" the gap was to intensify community involvement through the mobilization of a volunteer work force.
} 


\section{Hgrizons}

Table 1 Examples of CHBC Programs linked to those infected and affected

\begin{tabular}{|c|c|c|c|}
\hline $\begin{array}{l}\text { Models, } \\
\text { Definitions }\end{array}$ & Examples & Drawbacks & Advantages \\
\hline $\begin{array}{l}\text { Hospital } \\
\text { Outreach }\end{array}$ & $\begin{array}{l}\text { Lighthouse, Malawi: } \\
\text { Provides care and } \\
\text { support (HBC, VCT) to } \\
\text { people infected and } \\
\text { affected by HIV / AIDS } \\
\text { and to those suffering } \\
\text { from chronic illness. } \\
\text { Involves men as } \\
\text { caregivers. Clinical } \\
\text { care in the Lilongwe } \\
\text { Central Hospital. }\end{array}$ & $\begin{array}{l}\text { Costly; may be } \\
\text { stigmatizing; limited } \\
\text { coverage; delayed } \\
\text { services. }\end{array}$ & $\begin{array}{l}\text { Easy monitoring and } \\
\text { supervision; good } \\
\text { link with supplies; } \\
\text { access to } \\
\text { professional staff; } \\
\text { hospital referral } \\
\text { possible. }\end{array}$ \\
\hline NGO-based & $\begin{array}{l}\text { Wola Nani, South } \\
\text { Africa: Women and } \\
\text { their families are } \\
\text { supported with } \\
\text { psychosocial aspects of } \\
\text { care such as } \\
\text { acceptance, learning to } \\
\text { live positively, caring } \\
\text { for HIV-infected } \\
\text { children, dealing with } \\
\text { prejudice, } \\
\text { discrimination, grief and } \\
\text { bereavement. }\end{array}$ & $\begin{array}{l}\text { May not have structural } \\
\text { links with formal health } \\
\text { care system for supplies; } \\
\text { may be stigmatized if } \\
\text { AIDS-specific; } \\
\text { sustainability and } \\
\text { coverage difficulties. }\end{array}$ & $\begin{array}{l}\text { May provide } \\
\text { comprehensive } \\
\text { support through } \\
\text { community } \\
\text { volunteers; } \\
\text { accessible, } \\
\text { innovative and } \\
\text { flexible. }\end{array}$ \\
\hline Faith-based & $\begin{array}{l}\text { Catholic AIDS Action, } \\
\text { Namibia: provides } \\
\text { training to over } 1,200 \\
\text { home based care and } \\
\text { counseling volunteers } \\
\text { of various } \\
\text { denominations, who } \\
\text { serve orphans and the } \\
\text { community's sick and } \\
\text { needy. }\end{array}$ & $\begin{array}{l}\text { May moralize and } \\
\text { increase stigma; may not } \\
\text { be as focused on } \\
\text { physical needs; may not } \\
\text { have the needed skills; } \\
\text { eligibility may be } \\
\text { restricted based on } \\
\text { religious affiliation. }\end{array}$ & $\begin{array}{l}\text { Spiritual and social } \\
\text { needs addressed; } \\
\text { use existing } \\
\text { sustainable } \\
\text { networks and } \\
\text { volunteers; } \\
\text { affordable value for } \\
\text { prevention and care. }\end{array}$ \\
\hline
\end{tabular}




\begin{tabular}{|c|c|c|c|}
\hline $\begin{array}{l}\text { Community- } \\
\text { rooted care } \\
\text { providing } \\
\text { organizations are } \\
\text { a diverse group } \\
\text { extending } \\
\text { services to HIV- } \\
\text { infected } \\
\text { individuals at or } \\
\text { near their homes, } \\
\text { administered and } \\
\text { monitored by } \\
\text { health providers } \\
\text { and lay people. }\end{array}$ & $\begin{array}{l}\text { WOFAK, Kenya: home } \\
\text { based care program to } \\
\text { support carers in the } \\
\text { home and address } \\
\text { problems of home } \\
\text { based care. Nurses } \\
\text { and counselors visit } \\
\text { homes twice a week, } \\
\text { prescribe and distribute } \\
\text { drugs as needed; } \\
\text { explores traditional } \\
\text { healing to reduce the } \\
\text { cost and pain of } \\
\text { opportunistic infections. }\end{array}$ & $\begin{array}{l}\text { May be isolated from } \\
\text { supplies and hospital } \\
\text { backup; lack } \\
\text { technical and } \\
\text { supervisory input; } \\
\text { difficult when crises } \\
\text { occur; based on } \\
\text { volunteer labor of } \\
\text { women in the } \\
\text { community who are } \\
\text { already } \\
\text { overstretched. }\end{array}$ & $\begin{array}{l}\text { Use of existing } \\
\text { networks and } \\
\text { structures; affordable } \\
\text { and acceptable; } \\
\text { addresses prevention } \\
\text { also; may contribute } \\
\text { to stigma reduction; } \\
\text { can address other } \\
\text { chronic illnesses. }\end{array}$ \\
\hline $\begin{array}{l}\text { Networks of } \\
\text { People Living } \\
\text { with HIV/AIDS }\end{array}$ & $\begin{array}{l}\text { KENWA, Kenya: } \\
\text { Teaches home based } \\
\text { care techniques to } \\
\text { family members caring } \\
\text { for a person with AIDS; } \\
\text { sponsors income- } \\
\text { generating activities for } \\
\text { families affected by } \\
\text { AID; established two } \\
\text { small drop-in clinics } \\
\text { near slum } \\
\text { neighborhoods in } \\
\text { Nairobi. }\end{array}$ & $\begin{array}{l}\text { Members may feel } \\
\text { abandoned if no } \\
\text { other support; } \\
\text { ignores other chronic } \\
\text { illnesses in need of } \\
\text { care; they can } \\
\text { overextend } \\
\text { themselves and get } \\
\text { sicker, they also } \\
\text { have to deal with } \\
\text { stigma at least in } \\
\text { short term }\end{array}$ & $\begin{array}{l}\text { Personal understand- } \\
\text { ing; shared experi- } \\
\text { ences and } \\
\text { learning; shared } \\
\text { burden can reduce } \\
\text { stigma eventually } \\
\text { and mobilize } \\
\text { preventive actions. }\end{array}$ \\
\hline Self-help Groups & $\begin{array}{l}\text { "A friend in need", } \\
\text { Uganda: self-help } \\
\text { project of mainly } \\
\text { women and some men } \\
\text { carers to promote care } \\
\text { and support for persons } \\
\text { living with HIV and } \\
\text { orphans. It started with } \\
20 \text { families, now over } \\
50 \text { families. }\end{array}$ & $\begin{array}{l}\text { Isolated from local or } \\
\text { national } \\
\text { public/private } \\
\text { resources; limited/no } \\
\text { support from } \\
\text { outside. }\end{array}$ & $\begin{array}{l}\text { Grounded in the } \\
\text { household } \\
\text { and responding to } \\
\text { the needs } \\
\text { of the carers, } \\
\text { persons living } \\
\text { with HIV and } \\
\text { orphans. }\end{array}$ \\
\hline
\end{tabular}

\section{Issues of Scale and Coverage}

Most home and community-based care programs are small in scale and reach few of those in need. There are small programs that are very effective in the local community context in which they work, however, because they are small in scale, locally owned and responsive to changes in needs. Bigger, in the context of community home-based care, is not in every case better, and there are 


\section{Hgrizons}

concerns that simply expanding the scope of such programs might diminish their effectiveness. At the same time the need for care shows no sign of abating. Indeed it is generally agreed that efforts to care for those living with HIV/AIDS in their homes and communities need to "go to scale" as a matter of urgency. There is, therefore, a real and pressing need to examine the processes of "scaleup" and to consider ways of reaching more of those in need-both those infected and their caregivers-while maintaining (or improving) the quality and overall performance of a given effort. ${ }^{13}$

In recent years the call to scale up has been tempered by an awareness of the complexities involved and the need to proceed with caution and thoughtfulness (DeJong 2003). There are essentially two differing perspectives on scale-up. One view advocates for strong, centralized-or topdown-measures driven by outside agencies and/or national government programs. There are concerns, however, voiced by those with a more "bottom-up" orientation, that assistance provided by external agencies can (and does) undermine community initiative and motivation (Phiri et al. 2001). This more community-oriented perspective advocates for approaches that strategically target support toward strengthening existing systems and programs. This is the approach promoted by UNAIDS, who notes that "it is important that programs and policy are aimed at enhancing and strengthening the traditional coping responses of extended families and their communities" (UNAIDS 1999: 46), and also Phiri et al. (2001), who advocate for "the identification of programmatic methods and approaches, with analysis of strengths and limitations, for systematically mobilizing and strengthening the capacities of communities to respond to the needs of their most vulnerable children and households." Similarly, writing at an earlier phase of the epidemic, Barnett and Blaikie (1992: 109) were already finding that "it will be of the utmost importance that the coping capacity of households and communities is closely monitored in order that policies and programs are designed which can support them as their present coping mechanisms cease to be adequate. It will also be important that these policies and programs do not replace but build upon the experience of local people" (emphasis added).

From a caregiver perspective, a scale-up that accounts for constraints and incorporates and builds on existing resources would have clear advantages over an externally-driven approach. Existing programs that are scaled up could be more flexible and responsive to the ever changing needs of those caring for people living with HIV and AIDS in the home. Programs that provide care with an exclusive focus on the person living with HIV and AIDS could expand their reach by extending support services to family carers. Phiri et al. (2001) coin the phrase "scaling out" to refer to this process of "building on" existing programs. They contrast this demand-driven approach with "scaling up," which they argue is essentially supply oriented and driven by outsider agendas. Scaling-out, according to Phiri and colleagues, involves "the expansion of existing programming by implementing organizations which increases the number of families, communities and organizations being reached by effective services." This process involves the replication or expansion of programming to increase the coverage or scope through "awareness raising, training, exchange visits, technical support, strategic planning and capacity building." For a case study of an effective scaling out effort, see Appendix B.

\footnotetext{
${ }^{13}$ DeJong (2003) warns that it may not be possible in all instances to increase scope while maintaining quality. See her analysis, NGO Experiences of Scale-Up, for more detailed discussion of this issue.
} 


\section{Recent Developments: ART and Palliative Care}

\section{Antiretroviral therapy}

Many initiatives are currently evolving, aimed at increasing the availability of antiretroviral treatment (ART) in poor, highly affected countries. Among these are the Global Fund to Fight Malaria, TB and HIV; WHO's recent “ $3 \times 5$ Strategy," and the United States President's AIDS Initiative (PAI, formerly known as PEPFAR). These efforts are extremely new - most gaining momentum only since January 2004 - and so there is very little literature available. While the efforts to increase the availability and accessibility of these vital medical treatments is urgently necessary and to be welcomed, a concern with all these initiatives is that they have not incorporated a gender analysis into their design, and so may not be taking adequate account of the ongoing importance and prevalence of "unlinked care." More troubling is the possibility that the full force of attention being applied to this one domain of AIDS care (clinical), may cause the issue of home care to once again drop off the international (and therefore national) HIV/AIDS agenda. This would then undermine the preliminary and partial gains made toward mobilizing advocacy and action for meeting the full range of care needs of those living with HIV and AIDS, as well as the needs of unlinked family members who will continue to be tasked with their care.

There are a number of ways in which the increased availability and use of ART can have a positive impact on the "care economy" of affected households. Once people living with HIV start on therapy, there is a good chance that they will recover their health, enabling them to return to productive work, and so relieving the demands placed on their primary carer. In addition, the person receiving treatment may recover two to five years of healthy life, during which he or she can help the household regain its stability and to make arrangements to ensure the family is looked after following his or her death, through will-making and strengthening extended family ties.

However, ART does not obviate the importance of a caring household. Firstly, people on treatment may need support for treatment-taking. Because the regimes must be followed exactly as prescribed and can be difficult ot tolerate, the carer may need to keep records of the specific medications and doses the patient is taking, how they should be taken, and potential side effects. Carers can learn new skills, such as keeping drugs in divided pill boxes or making a chart showing what medicines to take, when to take them, and how much of each to take. Family carers may also need to help those taking the drugs to manage potential side-effects, which sometimes can be life threatening. Secondly, although the evidence is scant and somewhat contradictory, close family relationships may actually enhance the physical effects of treatment. At least one study undertaken in Switzerland set out to assess the relationship between stable partnership and clinical outcome in people living with HIV who were receiving highly active antiretroviral therapy (HAART) (Kim et al. 2004). This study found that those patients taking HAART who were in a stable partnership experienced a slower rate of progression to AIDS or death. This finding underscores the point that the importance of a caring home environment maintains relevance, even with the increased availability of medical therapies. Clearly, more research is needed on the interrelationships between ART and household well-being. 


\section{Hgrizons}

The third concern with the new initiatives is that although the policy language is broadly inclusive of women and gender concerns, it is not clear how this language will be operationalized, given the focus of these initiatives on reaching numerical targets. The World Health Organization's $3 \times 5$ strategy, for example, aims to have 3 million people on treatment by 2005. The goals of PAI are to have two million people on treatment, 10 million infections averted, and 7 million people in care by 2008 in 14 countries in Africa and the Caribbean. Focusing on the overall numbers of people on treatment without creating the conditions under which treatment access and adherence can be ensured (such as through stigma reduction, gender sensitivity, and strong support to household care providers) may undermine the effectiveness of these programs. Having 7 million people "in care" by 2008 could have a hugely beneficial effect on household care economies, but only if "in care" means access to programs that effectively link family care with good programs.

\section{Palliative care}

A recent Lancet editorial (Lancet 2003) asserts the following:

"For many the " $3 \times 5$ " initiative, if successfully implemented, will bring a longer life. But how useful is this and other antiretroviral-based initiatives to those people with AIDS in the developing world who will die today, tomorrow, or in the very near future? For these people, the stark reality is that it is too late for antiretroviral treatment; what they need, yet rarely receive, is palliative care."

Palliative care, which embraces a range of treatments, primary among which is pain-relief, is a vital but until very recently neglected area within HIV/AIDS. This is even true in high-income countries (see, e.g. Selwyn and Rivard 2003). "Good palliative care," the Lancet editorial asserts, "encompasses not just the patient but also the whole family," who are empowered through their access to skills and medications that will bring tangible relief to the people they are looking after. Through skilled management of pain and other symptoms of HIV/AIDS, good palliative care should also enable those who are sick to take a more active role in their households as their symptoms abate, and so could have a positive impact on the household care economy.

Ramsay (2003) offers an example of an exemplary home-based palliative care program called Hospice Uganda, which has been in operation since 1993. According to Ramsay, Uganda is the first and only African country so far that has incorporated palliative care for people living with HIV/AIDS and cancer into its national health plan. The provision of morphine for pain relief is a central component of this program. Hospice Uganda facilitates pain management for AIDS and cancer patients in their homes at a cost of about $\$ 11$ per week. Program participants are asked to contribute $\$ 2.50$, but about one third of participating families cannot afford this contribution, so are supported free of cost. The program operates through facility-based home care whereby a mobile team of nurses visits participants in their homes. Education is an additional component of Hospice Uganda's work, and the organization also provides pain management training to health professionals, village chiefs and local police throughout the country. As one Hospice educator explained: "Africa is in an epidemic of death, but palliative care is suitable and affordable to Africa and allows patients to die in peace and dignity" (Ramsay 2003). 


\section{Costs of Unlinked Care}

"Community-based care is not free of cost, and the effect on the lives of women should be calculated when such programs are evaluated" (Gilks et al. 1998: 139).

Studies of formal clinical treatment and care show that the costs can be substantial. However, the costs of formal clinical treatment are only dimension of the total costs of care. The costs of unlinked care have not been calculated, either on their own or as they contribute to programs. Thus, it can be argued that the costs of home care have been greatly underestimated, not least because they do not, as a rule, take account of both direct expenditures (medicines, transportation, labor time) and opportunity costs (e.g., foregone earnings) incurred at the household level as a result of caring for someone living with AIDS.

Indeed, providing care for a person living with HIV/AIDS imposes considerable costs on the patient, their carers and families. The costs to the household include financial resources, time resources and opportunity costs. The direct costs include, at a minimum, food and medicine, gloves, bandages, cleaning supplies, water, extra transport costs and labor costs. Households meet these costs in a number of ways, including altering household composition; withdrawing savings or selling assets; reallocating labor; withdrawing children from school; and depending on an extended family system and the community to support and help them (Desmond et al. 2000; Kongsin et al. 2000).

Steinberg et al. (2002) assessed the financial burden borne by households caring for an individual with HIV/AIDS. They surveyed 771 AIDS-affected households in South Africa and found that two-thirds reported a loss of income due to AIDS through increased expenditures on medications, and the high costs of funerals. Significant loss of income also resulted from carers' time being diverted from income generating activities and the inability of the sick person to generate income.

A full third of the remaining income in these homes was spent on healthcare needs, and on average these families spent four times their annual income on funerals. These expenses resulted in reduced spending on other necessities such as clothing and electricity, and a six percent reduction in expenditure on food: half of the families in the study reported that they are forced to go hungry sometimes due to lack of money to spend on food.

Hansen et al. (1994) studied four home care programs in Zimbabwe (two urban, two rural) and estimated the cost incurred by households in caring for a bedridden patient for three months as between Z\$556 and 841 (at that time, US\$68 to 103). The time burden on carers was estimated to impose the highest cost burden on households. Carers were found to be providing an average of 2.5 to 3.5 hours of care a day, or 17.5 to 24.5 hours per week. This time is therefore not available for food production, business activities, employment, education or the care and maintenance of other household members. The estimated household costs/opportunity cost stands at US\$22 per month.

The studies that have been undertaken to date on costs and benefits of home and community care are relatively few and provide only partial estimates. Much more work needs to be done to estimate the direct and opportunity costs and benefits. 


\section{Hgrizons}

\section{Non-Health Sector Responses}

The previous sections have highlighted some of the challenges facing carers in AIDS-affected households, how these challenges have been exacerbated by health service weaknesses, and how the CHBC movement has sought to mitigate these effects. Also touched upon were the potential contributions and limitations of new initiatives emerging onto the international HIV/AIDS agenda - the increased availability of antiretroviral therapies and palliative care. It is clear from the literature that whole household systems are affected by HIV/AIDS - that household well-being is undermined by the long-term, systemic effects of providing care for terminally ill, severely debilitated adults who would otherwise have been making substantive contributions to the household economy. Although individual households will do their best to mitigate these effects, the choices they are forced to make may further undermine their long-term viability and ability to withstand shocks. Such choices may include:

- Reducing consumption

- Sending children to live with relatives

- Replacing agricultural produce and meat with foraged vegetables

- Begging

- Migration in search of jobs

- Deepening debt through loans

- Sale of assets

- Use of savings

Donohue (1998) illustrates that the overall effect of HIV/AIDS on the economic well-being of affected households depends on the availability and size of household financial safety nets. The stronger the safety net, the better the chances that the household can withstand a crisis without having to take actions, such as those outlined above, that will further compromise its viability. Yet, many household safety nets are being eroded by the effects of the pandemic. Parker (2000) argues that the health of a family's safety net will depend on (1) the initial financial standing of the household, and/or (2) the ability of the household to build financial stability over time. Where these conditions do not exist, they need to be created in order for households to be able to weather the long-term impacts resulting from the pandemic. Health sector interventions are not well-placed to facilitate this kind of resource development, which is why researchers, policy makers and programmers are looking for ways to strengthen the economic foundations of households through the provision of social protections, effectively creating new safety nets to replace those that are no longer in place. These interventions include state-sponsored social protection programs, such as pension schemes, disability grants and social insurance; private sector schemes such as insurance programs; and NGO programs such as microfinance and micro-credit. By strengthening the economic resilience of households affected by AIDS, these programs have the potential to support both those living with HIV and AIDS and their carers.

A scan of the literature on social protections indicates, however, that many social protection programs that pre-dated AIDS are now encountering serious challenges. Encouragingly, lessons are 
being learned, and a number of innovations are beginning to take place to benefit affected households. In this section we briefly highlight some publicly financed social protections programs, but the focus will be on lessons learned on adapting programs to be effective in the context of HIV/AIDS in the non-governmental sector, specifically by microfinance initiatives, as they have the greatest relevance for the vast majority of poor households in poor countries. Food security issues will be touched upon briefly, and the efforts of one innovative project highlighted.

\section{1) State-sponsored social protection programs}

Many national governments in poor countries that are severely affected by the HIV/AIDS pandemic are unable to meet the increasing need for social protection programs. Economic reform programs have demanded cuts in public expenditures on social security and health. South Africa and Botswana are two of the few countries on the sub-continent that do have such programs - both countries provide "old age pensions" and South Africa also has a disability grants program. Steinberg et al. (2002) found, however, that in South Africa only very few of those formally eligible for these programs are actually accessing them. Their survey found, in fact that although all of the 771 households were eligible for at least one kind of government grant, and all of these households were linked to AIDS Service Organizations (ASO) who could help them access these grants, fewer than 16 percent of the households were doing so. The study did not formally assess the specific reasons why these households failed to access the assistance they were entitled to.

In Botswana, the situation appears to be quite different. Livingston (2003) reports that since 1997, citizens aged 65 and older have been eligible for a monthly payment of 100 pula (approx US\$23), with occasional cost of living increases. This money was intended as a supplement to family and household resources, and as a vehicle for empowering the elderly within their families by giving them cash of their own. Indeed, Livingston found that for many, this income provides a "much needed hedge against hunger and want." However, there have been a number of unintended consequences. In some cases, for example, adult children who formerly provided both monetary and emotional support ceased doing so when their elderly parents started to receive the pensions, directing scarce resources instead to the needs of their nuclear families. This redirection of resources up-ended the long-standing tradition of caring for one's elderly relatives and breached the social norms and expectations of older people that they would be provided for by their children in their old age. Because of these traditions, the elderly place a higher value on the money and care provided by family than that provided by the state, and so the reallocation of resources generated confusion and emotional distress to the elderly women interviewed (Livingston 2003: 217).

\section{2) Private sector social protections}

Women are increasingly being forced to leave their formal sector jobs for work in the informal economy as a result of their care-taking responsibilities or due to their own AIDS-related illness. At the same time, due to resultant absenteeism, it is harder for women to access and retain any type of work. As a result, women lose trading or production opportunities, lost income is not recovered, and debt burdens grow. This has critical, even crisis, implications for the household.

Employers are also affected by women's shifting of time to home care: absenteeism rates are high and productivity is reduced; in many cases, skills and experience are lost altogether as women are compelled to leave work. Most workplace programs that address HIV/AIDS do not include carers 


\section{Hgrizons}

in their schemes except as beneficiaries for certain treatment technologies. As far as we are aware, few, if any, employers have specific policies enabling workers to take care of family members sick and/or dying from HIV/AIDS - even in those countries most severely affected by the epidemic.

3) Non-governmental programs-Microenterprise initiatives

As van der Ruit (2001) points out, the vast majority of poor, AIDS-affected households have access neither to state-sponsored social protections, nor to the schemes set up by industry, necessitating the development or application of security efforts at community level. Microfinance initiatives (MFIs), it has been proposed, may be well placed to fill in the gap, and a number of analyses have examined the ability of various styles of conventional microenterprise initiatives to meet the changing needs of families affected by HIV/AIDS (Donohue 1998; Parker 2000; van der Ruit 2001; Teljeur 2002). These authors note an important tension that arises as a local AIDS epidemic matures, between what the institutions need to remain viable, and the needs of affected households. On the one hand, households may need the services of such initiatives more and more in order to create or strengthen their own safety nets. At the same time, conventional MFIs (such as credit and savings groups) are themselves at risk of collapse due to the changes in the circumstances of their clientele. Parker (2000), for example, notes that specific changes in MFI practice can include:

- Clients exiting the program or decreasing participation.

- Increased loan delinquency.

- Clients need for a wider range of financial services, especially safe and flexible savings programs.

- Client participation may depend on the ability to stop borrowing for a period of time or having flexible access to accumulated savings.

The epidemic can have direct impacts on institutions, such as increased absenteeism of staff due to sickness or care-giving, increased staff deaths to AIDS, and changes in portfolio quality due to increased delinquency in loan repayment. How then can MFIs both sustain themselves and facilitate the recovery and survival of households in the context of a mature or maturing HIV/AIDS epidemic? Parker (2000) is skeptical about whether a positive answer to this question can be found. Donohue (1998), however, maintains that to be effective and sustainable, microfinance programs should incorporate savings mobilization components and business development services that facilitate entrepreneurs' access to markets. Such innovations will allow participants to:

- Maintain or increase income flows, which can improve food security.

- Acquire secure, stable savings.

- Avoid the deployment of irreversible "coping" strategies, such as selling off key assets or divesting savings.

In a review of the economic responses of NGOs, CBOs, and communities to the epidemic in South Africa, Teljour (2002) outlines a range of community- and household-level interventions that have been suggested to enable families and communities to mitigate its multiple and complex impacts. Many of these same initiatives, if properly applied, could mitigate the impact of the epidemic on household care economies. The interventions highlighted include: 
Caldwell et al. (1993):

- Interventions that focus on building economic resources and supporting the creation of community safety nets (e.g., food banks, savings and loan groups, funeral societies).

UNAIDS (2000b):

- Increasing support to agricultural production.

- Expanding income generation opportunities.

- Decreasing demands on women's labor.

- Improving the welfare of children.

- Deploying conventional poverty alleviation mechanisms.

Box 3 provides a case study of an initiative that has successfully negotiated the institutional challenges posed by the epidemic to support households and individual carers. This program has specifically endeavored to overcome the potential pitfalls of "business as usual" microfinance initiatives outlined by Parker (2000). Specifically, the program has incorporated an HIV/AIDS focus, attention to gender, an understanding of the importance of social networks and long-term investment in communities. 


\section{Hgrizons}

\section{Box 3 SIMBA Project, CARE, Zimbabwe}

SIMBA offers self-managed savings-based microfinance services and basic management training to its members. The specific aim of this project is to promote economic development in communities affected by HIV/AIDS and to reduce the economic vulnerability of affected households and individuals (Jain 2003). An important innovation of this project is its targeting of five vulnerable groups: widows, orphans and youth, commercial sex workers, care providers, and people living with HIV and AIDS. Many of these individuals are primary livelihood earners in their households and/or household heads with multiple responsibilities for household well-being, including caregiving, despite their marginalized status. SIMBA partners with AIDS Service Organizations that organize care-providing services through community-based volunteers.

A key lesson learned by many microfinance initiatives is that AIDS-affected households are poor credit risks due to the many constraints they face and the many demands on their limited resources. For this reason, most such households could benefit more - at least until their stability is regainedfrom access to savings services. Thus, the principle underlying SIMBA is that community-managed and savings-based financial systems could provide much-needed services to these extremely vulnerable families at relatively low cost. Access to small, flexible loans would enable families to protect their assets, send children to school, and pay for medical or funeral expenses. In addition, the self-managed peer-groups could provide members with a much-needed source of social support, and eventually build "the self-confidence to earn their livelihoods with dignity" (Jain 2003: 4).

SIMBA's microfinance intervention is called Internal Savings and Loans (ISAL). This intervention enables community members to form self-selected savings groups and teaches them to manage the funds they generate. This approach enables community members to design products and services that best meet their own needs. Jain (2003) outlines seven dimensions of this program:

1. Group members combine their savings and create a revolving fund that provides small loans to group members.

2. Members can borrow from the revolving fund in times of financial emergency, such as paying school fees, medical expenses, food or funerals.

3. The group is trained to design its own loan criteria and norms.

4. The group itself manages the funds, so there are few administrative costs.

5. Market interest rates are charged on all loans and all the members share interest income that provides returns on savings, enabling the value of capital to be maintained in a high inflation environment.

6. The capital thus generated protects members against shocks and means they are not forced to sell off long-term assets.

7. The social support provided by the peer-group helps members to cope with the stigma associated with HIV/AIDS. By participating in the groups, members are protected from social isolation and given a sense of belonging and self-confidence. 


\section{An I ntegrated Management Approach}

As should be clear from the forgoing discussion, mitigating the impact of the pandemic on poor households in highly affected countries will be too much for any single sector or single type of intervention to undertake alone. Due largely to the current global political economy, national governments have increasingly coped by "downloading" the burden of caring for those living with HIV and AIDS onto communities and individual households. "Community-based care" has often been perceived as the solution to the crisis of care, resulting in a retreat of the public sector and increased dependence on non-governmental organizations to set up programs, even in the absence of evidenced-based good practices to model them on. Meanwhile, in the face of the devastation of AIDS, many communities and households in high prevalence areas are themselves increasingly unable to cope. As Steinberg et al. (2002:i) put it: "in already poor households, HIV/AIDS is the tipping point from poverty into destitution". Clearly, as Quinlan and Desmond (2002) point out, the strategy of downloading the burden of care on NGOs for CBHC is "ill-conceived." This is not to say, however, that CHBC does not have a fundamentally important role to play in mitigating the impacts of caring for those living with HIV and AIDS: "the issue in question is not whether to choose either state-based interventions or community-based solutions, but how to combine both sets of actions. The simple reason for advocating a combined initiative lies in the fact that community-based programs face many of the same practical problems as public health and welfare agencies" (Quinlan and Desmond 2002:36).

In Quinlan and Desmond's (2002) terms, a "combined" or "integrated" approach refers to a process of providing care and support, which fosters the use of limited resources to maximum advantage. In their review, they propose that "community-based projects have to combine health and welfare interventions" and suggest that non-governmental initiatives providing care to those living with HIV and AIDS and their families need to go hand in hand with state-sponsored efforts. At the very least, governments will need to be prepared to take on a "developmental role in the sense of creating an enabling environment in which families, communities and NGOs can work constructively" (Quinlan and Desmond 2002:38). The usefulness of this approach emerges particularly clearly when one views the issues through the care economy lens, bearing in mind that care, as we argued in the introduction, provides essential "public goods," and bearing in mind, too, that the needs of family carers will include but extend well beyond the scope of most community home-based care programs.

The call for the creation of a truly holistic and comprehensive care agenda is also being raised through listserv discussions such as the af-aids discussion entitled, "We want access to care, but what care?" (http://archives.hst.org.za/af-aids/msg01143.html). In this forum, discussants stressed the importance of a holistic approach that includes addressing basic needs. "Sanitation, clean water, and hygienic living conditions are essential elements of a holistic [care] approach, as are economic and psychosocial factors which impact on healthy, risk-free living." We would add to this list the adequate availability of food/nutrition, transport policy that enables carers to get to school and work, vocational training to improve income options, and social protection policies that can provide a safety net to those in greatest need. Clearly, NGOs will not be able to forward such an agenda alone. Governments will need to do more, with implications for national budgets. Homebased care provision needs to be supported as a part of development expenditure acknowledging 


\section{Hgrizons}

the interface with poverty reduction, health, education and sustainable development (HelpAge International 2003). And the international donors will need to make way for real progress through a range of measures, including meeting their commitments to increasing development assistance to .7 percent of GDP, granting debt relief, and reforming their own macroeconomic and trade policies to enable developing countries to achieve sustainable economic development. This breadth of response has been acknowledged in the UNGASS commitment, which states that it will be necessary to

“... adjust and adapt economic and social development policies, including social protection policies, to address the impact of HIV/AIDS on economic growth, provision of essential economic services, labor productivity, government revenues, and deficit-creating pressures on public resources."

Applying the spirit of Quinlan and Desmond's argument - that there is a need to combine state and community-based interventions - to the issue at the core of this paper, which is how best to link family caregivers to programs to facilitate their care work, we might adapt the situations depicted in Figure 1 as follows (Figure 3): 


\section{Figure 3}

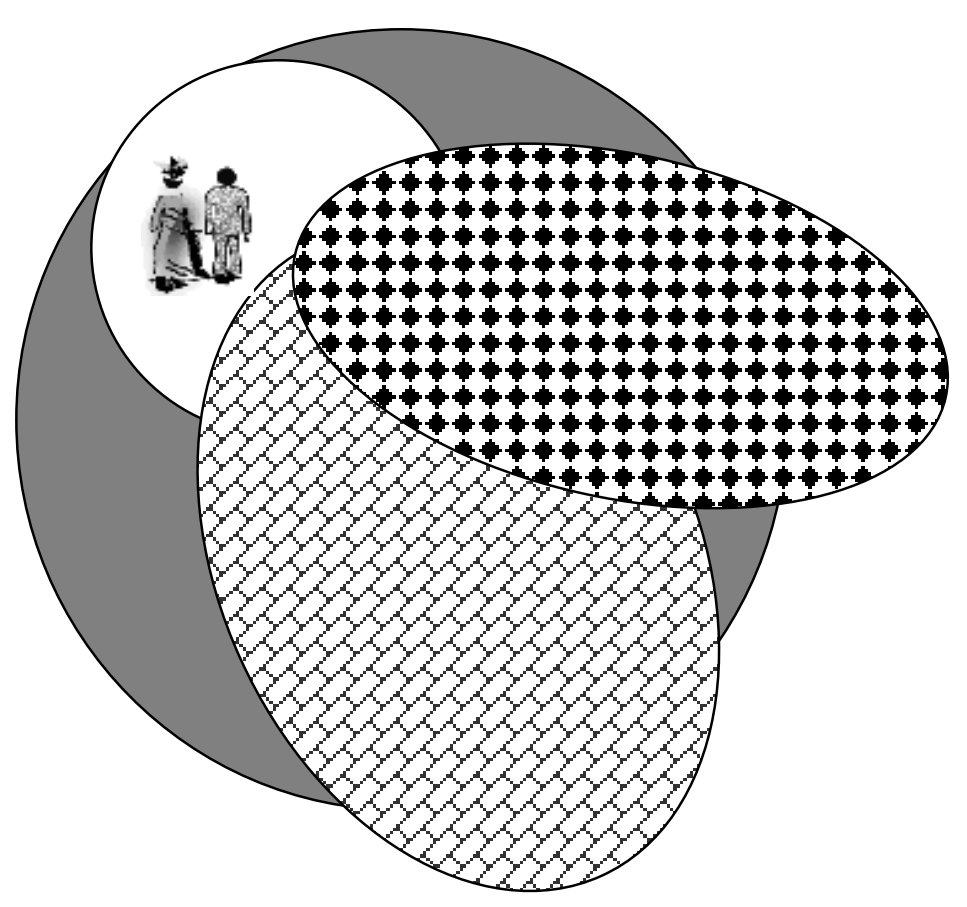

\section{Situation 5: An improved situation}

This model shows a greater share of the burden being taken by well-linked and well-supported CHBC programs (brick overlapping with checker). In addition, both the PLHA and family members (gray) are receiving clinical attention from the formal health care services (checker). Health service might, for example, be screening family members for tuberculosis, STDs and other infectious diseases. They may be getting treatment for symptoms of the physical demands of care such as back strain. They may be getting mental health support as well. The gray circle, the domain of family care, has shrunken considerably in relation to the other domains of care. Family members' time and energies can now be directed back into productive activities such as agriculture, income generation and education. PLHA are better supported and receiving improved quality of care, enabling them to think about will-making and spending quality time with children and family. They, too, may regain their health (e.g. through effective TB treatment or provision of $\mathrm{ARVs}$ ) and return to productive work or education.

Figure 3 represents a best-case scenario, where those living with HIV/AIDS have access to strong and effective facility-based and formal home-based care programs. These, in turn, are designed to benefit and support family care providers, enabling them to provide high quality care, love, and support to their affected family member(s), while at the same time maintaining productivity and sustaining education opportunities and wider social relationships. 


\title{
Hgrizons
}

\section{Conclusions and Recommendations}

\author{
"Home based care by family members is taken for granted. It's taken for granted \\ that women's labor is available and that it will be used, and that therefore \\ governments can somehow abdicate their responsibility. And whether that's home \\ based care or it's community based care, it's women-it's women on whose backs \\ all of this happens, and I just don't know whether there is enough of an \\ understanding of that fact.... But there has to be some support systems in place, \\ some resources, some supplies, some equipment. Households in Africa where \\ women are providing this care have no information, no gloves, nothing — nothing \\ to help them deal with the crisis that they're facing” (Msimang 2003).
}

This paper has reviewed the available literature addressing the domain of unlinked family care for HIV/AIDS, and found that, as the above quote clearly articulates, this caring work, undertaken primarily by women, is largely taken for granted by both governmental and non-governmental efforts to mitigate the impact of the disease. Unlinked care related to HIV/AIDS occurs in households alongside the other caring work that women do to sustain their families, communities and nations; but as the epidemic progresses, the burden of caring for those living with HIV and AIDS can overtake and displace the other crucial work of the care economy, leaving householdsand ultimately whole communities and nations - vulnerable to dissolution. Yet, the fundamental importance of this caring work continues to go unrecognized, as do its many costs for the women who undertake it.

In recent years international and national level policy makers have begun to recognize the need for a more coherent, expansive and inclusive "care agenda" for HIV/AIDS, that systems need to be put into place to help households and communities provide care for those who are sick and dying from AIDS. Prior to this time there was a "policy vacuum" (Gilks et al. 1998) on care and support for HIV/AIDS, resulting in the lack of an effective strategy to cope with the growing impact of the epidemic on the health sector, and lack of access to an appropriate level of care for those infected and affected. In order to fill this vacuum, Gilks and colleagues call for the development of a multisectoral approach, citing a publication in which such an approach is outlined (i.e. Barnett, Blas and Whiteside 1996). Speaking at the African Development Forum in Addis Ababa in 2000, Peter Piot, the head of UNAIDS, makes a strikingly similar point. In this speech Piot (2000) states that the care agenda is "unfinished" and advocates for a more multi-sectoral response.

The findings of this review resonate strongly with this perspective. Although many CHBC and social protection programs are in place, there is an urgent need for these programs to more effectively integrate with each other and to purposively link up with the domain of family care. It is vital, however, that this process of integration incorporates a gender perspective: the issues of care, treatment and support must be seen through the eyes of the women who are most often responsible for providing them. Our review found that the myriad gender and age impacts of unlinked care continue to be downplayed in policies and programs around HIV/AIDS care, and addressed in only a token fashion. This is the case despite widespread knowledge about the central role women of all 
ages play in the informal system of care, and a growing body of evidence on the particular needs and resources of older women and of children.

An important next step in the development of a more "linked up" agenda will be making clear distinctions between care that is provided through formal structures (e.g., clinical and non-clinical care provided in the home by volunteer lay providers) and care provided in the home that is not supported through formal programs (non-clinical care which is provided by family members, friends, and neighbors). As has been shown here, the contributions of untrained, unremunerated and unsupported family members (primarily women) to the care of people with HIV infection need to be seen as a distinct domain of care provision because the needs, resources and constraints of these providers are different, and because the mechanisms required for meeting those needs will be different.

So how can CHBC policies and programs be recast with unlinked care and the carer in mind?

- Integrate the unlinked system of care and the carer's perspective when applying UNAIDS best practices criteria (relevance, effectiveness, efficiency, sustainability and ethical soundness) to CHBC programs. These criteria are likely to be more gender responsive if they take needs of informal carers into account as well as the person living with HIV/AIDS.

- Integrate carers' needs across the project/program cycle, in program design (including consideration of costs and benefits to the carer in the household) and in program implementation.

- Ongoing monitoring and training are essential to strengthen capacity and to improve services. M\&E of programs which claim to support unlinked carers need to be conducted. Examples of programs that effectively link households to the formal system of care need to be identified, documented and disseminated.

This process should lead to an expanded scope of activities, incorporating a wider set of public and private sector issues, e.g. social protection, employment practices and policies, key public health infrastructures (water, sanitation, primary health care), agriculture, nutrition and housing. This shift in perspective will have budgetary implications at national and local levels in terms of allocation of spending and revenues to include consideration of the needs of informal caregivers.

It is clear that the "care agenda" is at long last advancing. There are an increasing number of voices from the community calling for more and better attention to the needs of those caring for people living with HIV/AIDS in their homes and the importance of facilitating and enabling this care, not taking it for granted. It will be vital for these voices to be heard at national and international policy levels, and that action on expanding the "care agenda" proceeds apace because of (if not despite) the increasing availability and accessibility of anti-AIDS drugs in poorer countries. 


\section{Hgrizons}

\section{Recommendations for Further Research}

This review has identified a number of gaps in research on the nature of care for those living with HIV and AIDS, and perhaps most importantly on the impacts of "unlinked care" on individual caregivers and their households. Specific areas for further research include the following:

1) Although there have been a few studies exploring the impacts of caring for someone living with HIV/AIDS, very few studies have attempted to quantify this impact through, for example, comparative time use surveys. Such studies would necessarily need to employ a "gender lens," exploring the differential impacts of care-giving on women and men; impacts across different age groups; and implications of shifts in time-use for the individuals and households involved. These studies need to focus on the impacts of illness rather than solely the impacts of death, which has been more thoroughly explored. Studies combining quantitative survey methods with ethnographic explorations would be of greatest value.

2) The unlinked system of care needs to be better understood and mapped and its costs assessed. In our review of the available literature, we found a surprising lack of research into the ways in which households are managing this illness. This lack of evidence is mentioned by others (e.g. Barnett and Whiteside 2002; UNAIDS 2000b; G. Foster, personal communication). There is an urgent need to map and study who the care providers are, what forms of care are they providing, what the costs and benefits of this care provision are for the various household members (including the carer his/herself and the person or persons they are caring for) and how the unlinked "system" of care interrelates with the formal system of CHBC. Such research would be of value in its own right, and could provide a much-needed evidence base for the evaluation of CHBC programs. As such, this work should be linked to CHBC program evaluations, as recommended below.

3) There is an urgent need to understand the role played by different types of CHBC programs in alleviating the burden of care borne by household members. CHBC program evaluations should assess the impact of their programs on household care providers as well as on those living with HIV and AIDS. Understanding the existing burden of care will enable programs to know how effective they have been in their provision of support.

4) Research exploring the ways in which gender roles and expectations may be shifting as households renegotiate the terms of the care economy in the context of the epidemic would be of value. This work could feed into identifying ways to support adolescent and adult men to assume a greater role in caregiving.

5) Cost-effectiveness analyses of CHBC programs need to incorporate an assessment of costs and benefits of participation to households. These costs and benefits should include both direct and opportunity costs. 
6) There are two potential directions in which international and national level HIV/AIDS policies could go vis a vis "care" in the context of increased availability and use of antiretroviral therapy in poor, highly affected countries:

- On the one hand, shifting the focus from prevention to treatment might provide an important re-direction of attention to the needs of those already suffering from HIV and their family members. This would potentially lead policy makers to begin to more systematically attend to the issues of HIV/AIDS care.

- On the other hand, however, the focus on treatment and the drive to meet specific targets might well detract from attending to the full range of issues that cluster around care.

- There is a need for studies exploring the ways in which the introduction and availability of ART is affecting households in the long-term.

- There is a need for studies exploring the ways in which other household members are involved in the treatment process and the implications of this involvement for their own well-being, the well-being of the person on treatment and of the broader household.

- Although many more people will have access to ART through such initiatives as WHO's $3 \times 5$ and the US government's PAI, the vast majority of those living with HIV/AIDS in poor countries will not. Studies are needed assessing the impacts of the ways in which the increased policy and programming focus on treatment is affecting the individuals and households not receiving ART.

- There is also a need for a comprehensive analysis of international and national level policies on ART on the extent to which they integrate gender concerns and the needs of the households in which those on treatment live. 


\section{Hgrizons}

\section{References}

Akintola, O. 2003. Health consequences of care-giving for caregivers of PLWAs in semi-rural South Africa. Paper presented at the Canadian Conference on International Health. October, 2003.

Ankrah, ME. 1991. AIDS and the social side of health. Soc Sci Med vol. 32(9): 967 - 980.

Barker, G. 2001. Gender equitable boys in a gender inequitable world: reflections from qualitative research and program development with young men in Rio de Janeiro, Brazil. Sexual and Relationship Therapy vol. 15(3): 263-282.

AED-USAID. 2003. Multisectoral Responses to HIV/AIDS: a compendium of promising practices in Africa. USAID-PVO Steering Committee on Multisectoral Approaches to HIV/AIDS. USAID Bureau for Africa, Office of Sustainable Development. April, 2003.

Barnett, T. 1991. On ignoring the wider picture: some confessions of an AIDS researcher/jobbing social scientist. Unpublished paper for the workshop on 'Relevance, Realism and Choice in Social Development Research'. University of Hull, 10-12 January, 1991.

Barnett, T. and P. Blaikie. 1992. AIDS in Africa: its present and future impact. Belhaven Press, London.

Barnett, T., E. Blas, and A. Whiteside. 1996. Integrating HIV/AIDS into sectoral planning. Geneva, World Health Organization.

Barnett, T. and A. Whiteside. 2002. Poverty and HIV/AIDS: Impact, coping and mitigation policy. AIDS, Public policy, and Child well-being. Cornia Andrea Giovanni, UNICEF: Chapter 11.

Beer, C., A. Rose and K. Tout. 1988. AIDS - the grandmother's burden. In Fleming et al. eds, The Global Impact of AIDS. Alan R. Liss, Inc. New York. pp.171-174.

Berman, C. 2002. Cindy Berman on gender, HIV, and the care economy, excerpted from the Women at Barcelona Care Economy listserv discussion. July 2002.

Berman, P., C. Kendall, K. Bhattacharyya. 1994. The household production of health: integrating social science perspectives as micro-level health determinants. Soc Sci Med 38 (2):205-15

Blinkhoff, P. et al. 1999b. Under the Mupundu Tree: Volunteers in home care for people with HIV/AIDS and TB in Zambia's Copperbelt. Strategies for Hope Series No. 14. ACTIONAID, London.

Budlender, Debbie. 2002. Why should we care about Unpaid Care Work? A guidebook prepared for the UNIFEM Southern African Region Office, Harare, Zimbabwe. December. 
Buvé, A. et al [short communication]. 1994. Mortality among female nurses in the face of the AIDS epidemic: a pilot study in Zambia. AIDS; 8: 396.

Caldwell J. et al. 1993. "African families and AIDS: Context, reactions and potential interventions”. Health Transition Review 3 (suppl):1-16

Carballo, M. and M. Carael. 1988. Impact of AIDS on Social Organization. In Fleming et al. eds, The Global Impact of AIDS. Alan R. Liss, Inc. New York. pp. 81 - 94.

Carswell, J.W.. 1988. Impact of AIDS in developing countries. Brit Med Bull. 44: 183 - 202)

Chela, C.M. 1995. Assessing the cost-effectiveness of home based care in Zambia. Paper presented at the $2^{\text {nd }}$ international Conference on Home and Community Care for Persons Living with HIV/AIDS, Montreal.

Dasgupta, P. 1993. An Inquiry into Well-Being and Destitution. Oxford: Clarendon Press.

DeJong, J. 2003. Making and Impact in HIV/AIDS: NGO experiences of scaling up. ITGD Publishing, London.

Desmond, C., K. Michael, and J. Gow. 2000. The hidden battle: HIV/AIDS in the household and community. South African Journal of International Affairs, 7(2):39-58

Donohue, J. 1998. 'Community-based economic support for households affected by HIV/AIDS.' Discussion Paper on HIV/AIDS Care and Support \#6, Arlington, VA: Health Technical Services (HTS) Project, for USAID.

Eberstein, I.W., W. Serow, and O. Ahmad. 1988. AIDS: consequences for families and fertility. In Flemming et al., eds. The Global Impact of AIDS. pp. 175-182.

Elson, Diane. 2002. "Macroeconomics and Macroeconomic Policy from a Gender Perspective." Paper Delivered at the Public Hearing of Study Commission on Globalization of the World Economy-Challenges and Responses. Berlin: Deutscher Bundestag, February 18.

1997. Economic paradigms and their implications for models of development: the case of human development. Chapter 5, in A. Berry, F. Stewart and R. Culpepper, eds. Global Governance and Development Fifty Years after Bretton Woods. New York, St. Martins Press. pp. 50-71.

England, P. and N. Folbre. 1999. The cost of caring. Annals of the American Academy of Political and Social Science 561: 39-51.

Esu-Williams, E. et al. 2003. Involving youth in the care and support of people affected by HIV and AIDS. Horizons Research Summary. Washington DC: Population Council.

Fleming, A.F. et al. 1988. The Global Impact of AIDS. Alan R. Liss, Inc. New York. 


\section{Hgrizons}

Folbre, N. 1999. Public Support for Parents. Unpublished manuscript. Amhurst College, Amhurst, Mass.

1994a. "Children as Public Goods." Papers and Proceedings of the American Economic Association. Vol. 84, No. 2, Nashville, Tenn.

\section{Routledge.}

1994b. Who Pays for the Kids? Gender and the Structures of Constraint. London:

Food and Agriculture Organization (FAO). 2003. HIV/AIDS and Agriculture: Impacts and Responses - Case Studies from Namibia, Uganda and Zambia. Rome: Food and Agriculture Organization.

. 2002. Gender and Access to Land. FAO Land Tenure Studies 4. Rome: Food and Agriculture Organization.

Foster, G. 2002a. Supporting community efforts to assist orphans in Africa. New Engl J Med, Vol. 346(24): $1907-1910$.

-2002b. Understanding Community responses to the situation of children affected by AIDS: lessons for external agencies. Draft paper prepared for the UNRISD project on HIV/AIDS and Development. March 2002.

Foster, S.D. 1995. The impact of HIV on the University Teaching Hospital, Lusaka, Zambia. World Hospitals, 31(1):18-21.

1994. Care and treatment of HIV disease in developing countries from a socioeconomic perspective. AIDS 8 (suppl 1): S341-S347.

Gilks, C. et al. 1998. Sexual Health and Health Care: care and support for people with HIV/AIDS in resource-poor settings. Health and Population Occasional Paper, Department For International Development, UK. London.

Guinness, L. et al. 2002. "Costs of hospital care for HIV-positive and HIV-negative patients at Kenyatta National Hospital, Nairobi, Kenya." AIDS 16(6): 901-8.

Haacker, M. 2001. Providing Health Care to HIV Patients in Southern Africa. IMF Policy Discussion paper, PDP/01/3.

Hansen, K. et al. 1994. The costs of hospital care at government health facilities in Zimbabwe with special emphasis on HIV/AIDS patients. Harare, Zimbabwe, Blair Research Institute, Ministry of health and family welfare. 
Hargreaves, J. et al. 2002. Social Interventions for HIV/AIDS Intervention with micro-finance for AIDS and Gender Equity. IMAGE Study Evaluation Monograph No. 1. University of Witwatersand, London School of Hygiene and Tropical Medicine and Small Enterprise Foundation.

Help Age International. 2003. Chapter 2: Age, gender and HIV, Help Age International.

Hong, K.T., T.V.A. Ngyuen, and J. Ogden. 2004. Understanding HIV and AIDS-Related Stigma in Vietnam. International Center for Research on Women Research Report. ICRW, Washington.

Jackson, H. 2002. AIDS in Africa: continent in crisis. SAfAIDS, Harare.

Jain, A. 2003. SIMBA: an initiative supporting the basic income and needs of HIV/AIDS-affected households and individuals. CARE Best Practices Series. CARE, USA.

Klaits, F. 2002. Housing the Spirit, Hearing the Voice: care and kinship in an Apostolic Church during Botswana's time of AIDS. PhD. Dissertation, Department of Anthropology, Johns Hopkins University.

Kim, J. et al. 2004. Stable partnership and progression to AIDS or death in HIV infected patients receiving active antiretroviral therapy: Swiss HIV Cohort Study. BMJ vol 328, 3 January 2004.

Kongsin, S. et al. 2000. The economic impact of HIV/AIDS on households in rural Thailand: The analysis of household coping strategies 13th International AIDS Conference, Durban

Lancet. 2003. Editorial. The untapped potential of palliative care for AIDS. Lancet vol. 362, no. 9398. 29 November 2003.

Livingston, J. 2003. Reconfiguring old age: elderly women and concerns over care in Southeastern Botswana. Medical Anthropology 22: 205-231.

McGrath, J.W. et al. 1993. AIDS and the urban family: its impact in Kampala, Uganda. AIDS Care $5(1): 55-70$.

Msimang, S. 2003. UNIFEM Cape Town Consultation, in partnership with the Positive Women's Network, and the Youth Against AIDS Network, May 2003 Cape Town

Msobi M and Msumi Z. 1999. Paper presented at the 13th International AIDS Conference, Durban.

Msobi, N. and Z. Msumi. 2000. HIV/AIDS and other chronic conditions: Home-based care cost study, Bagamoyo District, Tanzania International AIDS and Economics Network (IAEN)

Conference, Durban

Mutangadura, G. 2000. Household Welfare Impacts of Mortality of Adult Females in Zimbabwe: Implications for Policy and Programme Development. Paper presented at the AIDS and Economics Symposium organized by the IAEC Network, Durban, July 2000. 


\section{Hgrizons}

Nsutebu, E.F. et al. 2001. Scaling-up HIV/AIDS and TB home-based care: lessons from Zambia. Health Policy Plan. Sep;16(3):240-7.

Nyblade, L. et al. 2003. Disentangling HIV and AIDS Stigma in Ethiopica, Tanzania and Zambia. International Center for Research on Women, Washington, D.C.

Olenja, J. M. 1999. "Assessing community attitude towards home-based care for people with AIDS (PWAs) in Kenya." J Community Health 24(3): 187-99.

Onyx, J. and R. Leonard. 2002. Transforming Civil Society, Citizenship and Governance: The Third Sector in an Era of Global (Dis)Order. ISTR Fifth International Conference. Cape Town, South Africa / July 7-10, 2002

Osborne, C., E. van Praag, and H. Jackson. 1997. Models of care for patients with HIV/AIDS. AIDS 11 (suppl. B): S135 - S141.

Osborne, C. 1996. HIV/AIDS in resource-poor settings: comprehensive care across a continuum. AIDS vol. 10 (suppl. 3):S61-S67.

Parker, J. 2000. Discussion Paper: microfinance and HIV/AIDS. USAID Microenterprise Best Practices (MBP) Project.

Parker, R. et al. 2002 "HIV/AIDS-related stigma and discrimination: A conceptual framework and an agenda for action". Horizons Report. Washington, DC: Population Council.

Parkin, D. and D. Nyamweya (eds). 1986. Transformation in African Marriage. Manchester University Press, Manchester.

PANOS. 1990. Triple Jeopardy: women and AIDS. PANOS Institute, London.

Partnerships for care and support. The ILO Program on HIV/AIDS and the world of work (ILO/AIDS), International Labor Organization.

Phiri, S.N., G. Foster and M. Nzima. 2001. A Study to Explore ways to scale up effective, sustainable community mobilization interventions to mitigate the impact of HIV/AIDS on children and families. Paper prepared for the Displace Children and Orphans Fund of USAID. March 2001.

Piot, P. 2000. Keynote Speech at the "Setting the Scene" Plenary Session, African Development Forum, Addis Ababa, 4 December. http://www.uneca.org/adf2000/daily_updates/index.htm

Pizurki, H. et al. 1987. Women as Providers as Health Care, WHO, Geneva.

Procaare 2001. HCC: Stigma and Care: setting the scene.

http://old.healthnet.org/programs/procaare-hma/procaare.200109/msg00019.html 
Quinlan, T. and C. Desmond. 2002. Costs of Care and Support. In Literature Review: the economic impact of HIV/AIDS on South Africa. HEARD, University of Natal.

http://www.nu.ac.za/heard/papers/2002/costs\%20of\%20care.pdf

Ramsay, S. 2003. Leading the way in African home-based palliative care. Free Oral Morphine has Allowed Expansion of Model Home-Based Palliative Care in Uganda. Lancet vol. 362, no. 9398. 29 November 2003.

Russel, M. and H. Schneider. 2000. A Rapid Appraisal of Community-Based HIV/AIDS Care and Support Programs in South Africa. Health Systems Trust/Center for Health Policy, University of Witwatersrand, Johannesburg, South Africa.

Selwyn, P.A. and M. Rivard. 2003. Palliative Care for AIDS: challenges and opportunities in the era of highly active anti-retroviral therapy. J. Palliat Med. Jun; 6(3): 475-87.

Seeley, J. et al. 1993. "The extended family and support for people with AIDS in a rural population in south west Uganda: a safety net with holes?" AIDS Care 5(1): 117-22.

Shawky, A. 1972. Social work education in Africa. International Social Work, 15: 4-5.

Steinberg, M. et al. 2002. Hitting Home: How Households Cope with the Impact of the HIV/AIDS Epidemic. A survey of Households affected by HIV/AIDS in South Africa, ABT Associates.

Taylor, L., J. Seeley, and E. Kajura. 1996. "Informal care for illness in rural southwest Uganda: the central role that women play." Health Transit Rev 6(1): 49-56.

Teljour, E. 2002. Response of non-governmental organizations, community-based organizations and communities. In K. Kelly, W. Parker and S. Gelb, eds. HIV/AIDS, Economics and Governance in South Africa: key issues in understanding response. Center for AIDS Development, Research and Evaluation/Joint Center for Political and Economic Studies. USAID.

Trengove, Jones T. 2001a. Who cares? AIDS Review, 2001. University of Pretoria, Center for the Study of AIDS.

UNAIDS. 1999. A review of household and community responses to the HIV/AIDS epidemic in the rural areas of sub-Saharan Africa. Geneva, Switzerland, UNAIDS.

- 2000a Caring for Carers: managing stress in those who care for people with HIV and AIDS. UNAIDS Case Study, Best Practice Collection. May 2000.

-2000b. A review of household and community responses to the HIV/AIDS epidemic in the rural areas of sub-Saharan Africa. UNAIDS, Geneva.

2001. AIDS epidemic update. UNAIDS, Geneva. 


\section{Hgrizons}

- 2002. Report on the global HIV/AIDS epidemic. UNAIDS, Geneva.

Uys, L. 2003. Guest editorial: longer-term aid to combat AIDS. J Adv Nurs. 44(1):1-2

van de Ruit, C. 2001. HIV/AIDS, the informal economy, and social protection: experiences from South Africa. Discussion document for the ILO/UNIFEM workshop on the Care Economy, HIV/AIDS and the World of Work. 22-23 November 2001.

van Praag, E. 1995. The continuum of care: lessons from developing countries. IAS Newsletter, November 1995, 3:11-13.

WHO. 2000a. Fact sheets on HIV/AIDS for nurses and midwives. www.nt.who/whosis/statistics/factsheets_hiv_nurses

- 2000b. Home based long-term care: report of a WHO study group. WHO Technical Report Series 898. World Health Organization, Geneva.

- 2000c. Key elements in HIV/AIDS care and support. World Health Organization, Geneva.

—. 2000d. "Women and HIV/AIDS" World Health Organization, Geneva.

www.who.in/inf-fs/en/fact242.html

- 2002a. Developing and Validating a Methodology to Examine the Impact of HIV/AIDS on Older Caregivers. World Health Organization, Geneva.

_ 2002b. Guidelines on Care and Support in Resource Limited Settings. World Health Organization, Geneva.

- 2002c. Policy Framework for Community Home-Based Care in Resource Limited Settings. World Health Organization, Geneva.

WHO and Zambian Ministry of Health. 1994. Cost and Impact of Home-based Care for People Living with HIV/AIDS in Zambia. World Health Organization, Geneva. 


\section{Appendix A Community and Home-based Care Programs}

\section{Psychosocial Support for Carers in the Home: Wola Nani}

In South Africa, Wola Nani has been in existence since 1994 to respond to the growing AIDS crisis and to offer help and support women with dependent children in poor communities who are historically disadvantaged and economically marginalized. At this time, Wola Nani implements client-driven income generation, individual and peer group counseling, family care education, child care, and home care visits. At Wola Nani, women and their families are helped with the critical psychosocial aspects of care such as acceptance, learning to live positively, caring for HIV-infected children, dealing with prejudice, discrimination, grief and bereavement. The counseling services include individual and family counseling, bereavement counseling, peer support, HIV education, primary health care training, home visits and health monitoring. Since its beginning, thousands of HIV-infected individuals and families have benefited from Wola Nani's work in the field. Every six months, the project organizers undertake an internal evaluation of their programs. Based on the results of these evaluations, modifications, if necessary, to the strategic plans are made.

Source: http://www.who.int/hiv/pub/prev_care/PsychosocialSupport.pdf

\section{HI V/ AI DS Home-Based Care and Counseling Project in the Gambia}

Worldwide Evangelization for Christ International (WEC) is a faith-based organization supported by Catholic Relief Services on a HIV/AIDS Home Based Care and Counseling Project in the Gambia. Beginning in 1999, WEC has been helping individuals and local communities provide assistance to people living with AIDS and to Gambian communities that have been affected by the AIDS pandemic. Their support includes free voluntary counseling and testing services, training of community leaders, sensitization of communities about HIV/AIDS, provision of support and care for people living with HIV and other chronic illnesses. So far WEC has been able to train 30 community leaders and 60 other key players at the community level; train traditional communicators involved in sensitizing communities on HIV/AIDS and on how to respond to people who are infected or affected by the illness; train male and female peer health educators in the villages. Most of these young people also provide support to chronically ill patients at home. Registered over 200 chronically ill patients since the beginning of the project, all of whom have received a continuum of care from the community to the hospital level. (Due to the strong stigmatization of HIV/AIDS in The Gambia, it is important that the term "chronically ill" is used rather than HIV-positive or AIDS patient in order to protect the privacy of project clients.)

Source: www.catholicrelief.org 


\section{Targeting Caregivers in the Home: Women Fighting AI DS in Kenya (WOFAK)}

WOFAK is a Kenyan national NGO, with a mission of supporting women and children living with and affected by HIV/AIDS. The support includes counselling, medical, nutritional and other forms of material support. WOFAK developed a home-based care program to support the carers in the home and address problems associated with home-based care. They identify the problems as: increased medicinal expenses, premature discharge from hospitals, lack of funding to support patients, and isolation from familial and community support. WOFAK created homebased care teams, consisting of nurses, caregivers, and counselors that visit homes twice a week, and prescribe and distribute drugs as needed. Through educational materials and discussion, the program encourages openness in the family and community to reduce the stigma felt by homebased care patients. WOFAK also explores alternative therapy and traditional healing as a means to reduce the cost and pain that accompany opportunistic infections associated with HIV/AIDS. In 1999, WOFAK worked in collaboration with the Kenya Forestry Research Institute to investigate the use of herbal plants to help treat patients. WOFAK trains traditional healers to provide HIV/AIDS counseling and administer herbs to treat symptoms associated with AIDS. The program has developed income generating activities (IGAs), such as selling charcoal and firewood, second-hand clothes and shoes, dried and smoked fish, and fruits and vegetables. These IGAs give the women some financial security and help them provide for their families.

Source: Global Fund for Women Website (www.globalfundforwomen.org) 


\section{Appendix B Scaling Up YRG Care}

Founded in 1993 in Chennai, YRG CARE offers HIV voluntary counseling and testing; psychosocial counseling for clients, couples, and families; nutrition counseling; inpatient and outpatient care, including treatment for opportunistic infections; and home care. The YRG CARE scale up effort at four sites in South India is based on "concept replication", or transferring core values - such as patient-centered care, respect for client dignity and confidentiality, and the involvement of families and communities - to new settings. This approach allows the partners the flexibility to design each scale-up program along the pathway most appropriate to each site's needs and concerns. The concept replication approach acknowledges that concepts and values rather than rigid organizational structures and models are the critical elements to export to a new environment. A scale-up process based on building the capacity of organizations and service providers was deemed necessary to bridge the wide gap between the need for a client-centered approach and the top-down tradition of service planning and management in India. YRG CARE started by working with its scale-up partners to identify needs and goals, then developing a training and capacity-building program tailored to each site, conducted by YRG CARE's knowledgeable staff. Rather than having external consultants take charge, an indigenous NGO that speaks the language, understands the culture, and has experienced the challenges of doing this work in the region led the way. YRG CARE chose a wide variety of scale-up partners - from a mission hospital to a business selling medical equipment and lab services - for a good mix of natural variation that would broaden lessons from the study findings. Training covered three areas: clinical services (HIV disease management, prevention of mother-to-child transmission, VCT, nursing, and more), psychosocial services (pre- and post-test counseling, family and couple counseling, nutrition, and grief counseling), and organizational development (resource mobilization, proposal writing, record keeping, advocacy). The training itself was offered in several formats: on-site training for individual partners, centralized training for all partners, hands-on training at YRG CARE's facilities, mentoring, and site visits among partners. A key emphasis of the capacity building was identification of local care, treatment, and support partners with complementary capacities with whom the scale-up partners could collaborate and thus avoid duplicating services. YRG CARE's emphasis on reinforcing and expanding referrals and networking with other service providers has also helped the partners recognize the value of collaboration and get more mileage out of their programs.

Source: http://www.popcouncil.org/pdfs/horizons/yrgcrsclngup.pdf 


\section{Hgrizons}

Horizons is a global operations research program designed to:

- Identify and test potential strategies to improve HIV/AIDS prevention, care, and support programs and service delivery.

- Disseminate best practices and utilize findings with a view toward scaling up successful interventions.

\section{(2) Population Council}

Horizons is implemented by the Population Council in collaboration with

- International Center for Research on Women (ICRW)

- International HIV/AIDS Alliance

- Program for Appropriate Technology in Health (PATH)

- Tulane University

- Family Health International (FHI)

- Johns Hopkins University

For more information, please contact:

Horizons Program, Communications Unit 4301 Connecticut Avenue, NW Suite 280 Washington, DC 20008 USA

Tel: 202-237-9400

Fax: 202-237-8410

Email: horizons@pcdc.org www.popcouncil.org/horizons 